\title{
CONTROL DE LA COLESTEROLEMIA EN ESPAÑA, 2000 UN INSTRUMENTO PARA LA PREVENCIÓN CARDIOVASCULAR
}

\author{
Ministerio de Sanidad y Consumo, Sociedad Española de Cardiología y Sociedad Española de Arterioesclerosis.
}

\section{RESUMEN}

El documento «Control de la Colesterolemia en España, 2000. Un instrumento para la Prevención Cardiovascularn revisa la evidencia existente en el campo de la prevención cardiovascular y los avances terapéuticos producidos en los últimos años. con el objetivo de ayudar a tomar decisiones clínicas basadas en el riesgo cardiovascular.

Las enfermedades del aparato circulatorio son la primera causa de muerte en España, originando casi el $40 \%$ de todas las defunciones. En los últimos años se ha producido un descenso de las tasas ajustadas de mortalidad por enfermedades del aparato circulatorio, pero el número de muertes por cardiopatía isquémica está aumentando debido fundamentalmente al envejecimiento de la población. La menor mortalidad por cardiopatía isquémica unido al aumento de la incidencia de dicha enfermedad ha condicionado que actualmente sea la primera causa de consulta hospitalaria. El impacto demográfico, sanitario y social de estas enfermedades está aumentando y va a continuar haciéndolo en las próximas décadas.

El adecuado tratamiento de la hipercolesterolemia y del resto de los factores de riesgo es fundamental para prevenir las enfermedades cardiovasculares. Las acciones concretas a realizar dependen del riesgo de enfermar. La estratificación del riesgo de las personas es esencial, por cuanto condiciona la periodicidad del seguimiento y la intensidad del tratamiento.

Basándose en dicha estratificación se han establecido unas prioridades de control de la colesterolemia y del riesgo cardiovascular derivado de la misma. Los grupos de intervención ordenados de mayor a menor prioridad son los siguientes:

1. Prevención Secundaria: Pacientes con enfermedad coronaria establecida u otras enfermedades ateroscleróticas.

2. Prevención Primaria: Personas sanas, pero con riesgo alto de desarrollar enfermedad coronaria u otra cnfermedad aterosclerótica, porque presentan una combinación de factores de riesgo- entre ellos están la dislipemia (colesterol total y cLDL elevados, cHDL bajo y triglicéridos elevados), el tabaquismo, la elevación de la presión arterial, la elevación de la glucemia y la historia familiar de enfermedad coronaria prematura- o porque presentan una elevación muy importante o forma grave de un solo factor de riesgo, como la hipercolesterolemia u otras formas de dislipemia, hipertensión arterial o diabetes.

3. Familiares de primer grado de pacientes con enfermedad coronaria de aparición precoz u otras formas de enfernedad aterosclerótica.

4. Otras personas a las que se accede en el curso de la práctica clínica habitual.

En prevención primaria en los pacientes de riesgo alto (riesgo igual o superior al $20 \%$ - según la tabla de riesgo las Sociedades Europeas de Cardiología, Aterosclerosis, Hipertensión - o personas que presentan dos o más factores de riesgo - National Cholesterol Education Program II -) el objetivo terapéutico se establece en un cLDL inferior a $130 \mathrm{mg} / \mathrm{dl}$. En prevención secundaria el tratamiento farmacológico se instaurará con un $\mathrm{cLDL}^{3} 130 \mathrm{mg} / \mathrm{dl}$ y el objetivo terapéutico será cLDL $<100 \mathrm{mg} / \mathrm{dl}$.

Las estatinas son los fármacos de primera elección en el tratamiento de la hipercolesterolemia. Cuando exista hipertrigliceridemia moderada-grave y cHDL bajo se emplearan los fibratos. En el síndrome coronario agudo el tratamiento hipolipemiante, cuando esté indicado, debe iniciarse precozmente.

Los pacientes con cardiopatía isquémica se deben incluir en programas de prevención secundaria que aseguren, de forma continuada, un buen control clínico y de los factores de riesgo, con fármacos con una ruzón coste-efectividad adecuada.

\section{ABSTRACT}

Cholesterolemia Control In Spain, 2000. A
tool for Cardiovascular Disease Prevention

The report «Cholesterolemia Control In Spain, 2000. A tool for Cardiovascular Disease Preventions reviews current evidence on cardiovascular prevention and therapeutical advances occurred in the last years, in order to help overall risk-based clinical decision-making.

Cardiovascular disease ranks as the first cause of death in Spain, accounting for almost $40 \%$ of total mortality. During the last years ageadjusted cardiovascular death rates have been declining, but the absolutc number of deaths by coronary heart disease is ascending due mainly to the population aging. Coronary heart disease is the first cause of hos pital consultation due both to the lesser coronary heart disease mortality and to the increase in coronary heart disease incidence. The demographic, health and social impact of cardiovascular disease is increasing and it is likely to go on in the next decades.

Appropriate treatment of high blood cholesterol and of other major modifiable risk factors is crucial for preventing cardiovascular disease. Specific actions to carry out depend on the risk to get ill. Individual risk stratification is essential as it determines the follow up periodicity and treatment intensity.

Priorities of control of cholesterolemia and its consequent risk are based on risk stratification. The groups for intervention are ordered in a descendent priority hierarchy as follows:

1. Secondary prevention: Patients with established coronary heart disease or other atherosclerotic disease.

2. Primary prevention: Healthy individuals who are at high risk of developing coronary heart disease or other atherosclerotic disease, because of a combination of risk factors - including lipids (raised total cholesterol, and LDL-cholesterol, low HDL-cholesterol and raised triglycerides), smoking, raised blood pressure, raised blood glucose, family history of premature coronary disease - or who have severe hypercholesterolaemia, or other forms of dyslipidaemia, hypertension or diabetes.

3. Close relatives of patients with early onset coronary heart dise ase or other atherosclerotic disease.

4. Others individuals met in connection with ordinary clinical practice.

In primary prevention, the therapeutic objective in high risk patients (risk ${ }^{3} 20 \%$-upon the risk chart of the European Societies of Cardiology, Atherosclerosis, Hypertension- or individuals with 2 or more risk factors -National Cholesterol Education Program II-) is set up at $\mathrm{LDL}$-cholesterol $<130 \mathrm{mg} / \mathrm{dl}$. In secondary prevention, the drug treatment will be indicated when LDL-cholesterol ${ }^{3} 130 \mathrm{mg} / \mathrm{dl}$ and the therapeutic objective will be LDL-cholesterol $<100 \mathrm{mg} / \mathrm{dl}$.

Statins are first line drugs for treatment of high blood cholesterol. Where moderate-severe hypertrigliceridemia or low HDL-cholesterol fibrates are prefered. In acute coronary syndrome hypolipemiant treatment, where indicated, should be used as soon as possible.

Coronary heart disease patients should be offered secondary prevention programmes which provide, in a continuous manner, a good clinical and risk factor control, with appropriate cost-effectiveness drugs 


\section{PRÓLOGO}

España ha conseguido alcanzar el Objetivo de Salud para Todos en el año 2000, establecido por la Oficina Regional Europea de la Organización Mundial de la Salud, en relación con la reducción de la mortalidad por las enfermedades cardiovasculares. A pesar de ello, las enfermedades cardiovasculares son la primera causa de muerte en España. Ahora se debe proseguir el camino iniciado para afrontar el reto de conseguir el objetivo fijado por la OMS en «Salud para todos en el siglo XXI». En esta línea de actuación se encuadra la elaboración, publicación y difusión del documento «Control de la Colesterolemia en España, 2000. Un instrumento para la prevención cardiovascular», que aborda uno de los principales factores de riesgo cardiovascular.

En la década transcurtida desde que se editó el «Consenso para el Control de la Colesterolemia en España» se han publicado numerosos y relevantes trabajos sobre prevención cardiovascular. Esto ha hecho necesario preparar un nuevo documento que revise estos estudios y presente una serie de recomendaciones adaptadas a la situación española, que sirvan de orientación para la detección, tratamiento y seguimiento de la hipercolesterolemia, desde una perspectiva multifactorial basada en el riesgo cardiovascular. Se trata de disponer de un documento que sea útil a los profesionales sanitarios en la práctica clínica cotidiana, y que les sirva de guía y ayuda para realizar las actividades de prevención primaria y secundaria cardiovascular, no pretendiendo, por tanto, constreñir su labor sino, todo lo contrario, facilitar su trabajo.

Esta iniciativa de la Dirección General de Salud Pública del Ministerio de Sanidad y Consumo, parte de una propuesta de la Socie- dad Española de Cardiología, a través de su Sección de Cardiología Preventiva y Rehabilitación, y de la Sociedad Española de Arteriosclerosis. Para hacer más ágil y eficiente el proceso de elaboración, se constituyó un pequeño grupo redactor, formado por expertos del Ministerio de Sanidad y Consumo, Sociedad Española de Cardiología, Sociedad Española de Arteriosclerosis y otros especialistas a lítulu individual, yue elaboraron un primer borrador. Éste se envió, como documento abierto y sujeto a discusión, a numerosas Sociedades Científicas, Asociaciones e Instituciones implicadas y a expertos en la materia, para que realizaran propuestas y modificaciones. Todo ello ha permitido mejorar el texto y alcanzar un alto grado de acuerdo, aunque en algunos casos las observaciones realizadas no han podido ser asumidas plenamente, al ser mayoritaria la opinión que en el documento se recoge. Por tanto, el documento que aquí se presenta es el resultado del máximo nivel de consenso posible entre todos los participantes.

Una vez publicado el documento, se inicia la fase crucial de difusión del mismo, con objeto de que pueda llegar a sus destinatarios, los profesionales sanitarios. En ella, todas las entidades y personas involucradas en su elaboración pueden ejercer una labor sustancial.

Finalmente, quisiera agradecer a todos los participantes su valiosa colaboración y el esfuerzo realizado, que ha quedado plasmado en este documento, y ofrecer, una vez más, la colaboración del Ministerio de Sanidad y Consumo para desarrollar estas iniciativas.

Juan José Francisco Polledo Director General de Salud Pública Ministerio de Sanidad y Consumo 


\section{PRESENTACIÓN}

Las enfermedades cardiovasculares constituyen en España, al igual que ocurre en otros países del mundo denominado desarrollado, la primera causa de muerte, $\mathrm{y}$ entre las medidas que más han contribuido a la disminución de las cifras de mortalidad ajustadas por edad en estos países, la reducción de las cifras medias de colesterol en la población ha sido una de las más importantes. Por otro lado, en estos últimos años se han realizado ensayos clínicos que han demostrado que la reducción de las cifras de colesterol en las personas con riesgo elevado, utilizando modificaciones en la dieta y fármacos adecuados, consigue reducir el riesgo individual de muerte por enfermedades coronarias y cerebrovasculares.

Teniendo en cuenta lo anterior, era evidente la necesidad de realizar un nuevo documento de consenso acerca del Control de la Colesterolemia en España, como instrumento para la prevención cardiovascular, dado que el documento previo fue realizado diez años antes, y un documento de estas características lleva impreso en sus páginas la caducidad por mor de los cambios que se experimentan en el conocimiento y tratamiento de cualquier situación médica.

En nuestro país se han realizado diversos estudios de Prevención Cardiovascular, en los que nuestra Sociedad ha tenido un papel de liderazgo. En prevención primaria, el documento del Colesterol de Niños y Adolescentes mostró la realidad preocupante del cambio de alimentación y de hábitos de vida de los niños españoles y dio las pautas para el manejo de la hipercolesterolemia en esta edad. En prevención secundaria existen diversos estudios a nivel nacional como el PREVESE (Prevención de la Enfermedad Vascular en España) y en comunidades autónomas como el RIGA (Riesgo de Infarto en Galicia), que auditan el manejo de la prevención secundaria de las enfermedades cardiovasculares en nuestro medio. Todos ellos muestran que existe una importante pérdida de oportunidades para reducir el impacto de la enfermedad cardiovascular por falta de un adecuado manejo de la colesterolemia en personas de alto riesgo, de modo especial dentro de la denominada prevención secundaria.

Este documento debe, sin duda, contribuir a cerrar el hiato existente entre el conocimiento científico y la práctica clínica. En su redacción han participado representantes del Ministerio de Sanidad y Consumo, que han aportado eficaz ayuda y sobrada experiencia, los expertos en este campo del conocimiento, y que, junto con otros ponentes, han cooperado de forma eficaz en la redacción final de un documento de consenso, en el cual se ha tenido que buscar el necesario equilibrio entre diferentes opciones, aunque sin perder el rigor necesario imprescindible. Estas características, unidas a la claridad de presentación, hacen del mismo un documento de referencia y de enorme utilidad que contribuirá a «mejorar la calidad de vida de los españoles disminuyendo el impacto de las enfermedades cardiovasculares», como reza en la misión de la Sociedad Española de Cardiología y Fundación Española del Corazón.

Como presidente de la Sociedad Española de Cardiología debo expresar la satisfacción de haber contribuido a su realización. Nuestra Sociedad, desde su fundación, tiene como objetivo primordial la prevención de las enfermedades cardiovasculares y, de modo especial, de la cardiopatía isquémica y las restantes complicaciones de la arteriosclerosis. A través de la Sección de Cardiología Preventiva, contribuye de forma importante a mejorar el control de los factores de riesgo cardiovascular de las enfermedades cardiovasculares y en particular la hipercolesterolemia. En esta Sección nació la idea y se tomaron las iniciativas pertinentes para la elaboración del presente documento.

Por todo ello es satisfactorio poder presentar el resultado de una iniciativa que, realizada en colaboración con otras Sociedades e Instituciones, contribuirá, sin duda, a mejorar la salud de los ciudadanos españoles.

Alfonso Castro Beiras Presidente de la Sociedad Española de Cardiología 
La arteriosclerosis es la causa subyacente a las enfermedades cardiovasculares, cerebrovasculares y vasculares periféricas. Dichas enfermedades son la causa más común de muerte en los países industrializados y en numerosos países en vias de desarrollo. Además, las predicciones sobre el impacto de las enfermedades cardiovasculares en la salud para los próximos veinte años siguen siendo igual de desalentadoras. Numerosos ensayos clínicos multicéntricos han demostrado la gran eficacia del control de los lípidos plasmáticos en la prevención de la cardiopatía isquémica; sin embargo, este control no está completamente asumido en la práctica clínica. Asimismo, el diagnóstico global de riesgo es un concepto que debe adaptarse a tiempo y lugar. Este documento es el resultado del trabajo de un grupo de profesionales, que han dedicado sus mejores esfuerzos en dar forma a un consenso sobre un tema de gran impacto médico y social en nuestros días. La búsqueda de la salud cardiovascular y la mejora en la calidad de vida ha sido la primera intención de dicho trabajo y, como tal, hay que felicitarles por el mismo. Es evidente que después de diez años, los conocimientos adquiridos en nuestro campo eran valedores de la revisión del tema, y que la aplicación de la directrices internacionales debe adaptarse a la situación de nuestro país en la medida de lo posible.

La necesidad de este documento se ha visto impulsada por los importantes avances en tratamiento médico para la prevención de las manifestaciones clínicas de la arteriosclerosis. Ia International Atherosclerosis Society, American Heart Association, European Athe- rosclerosis Society y European Society of Cardiology, han desarrollado guías para el tratamiento médico en pacientes con enfermedad cardiovascular establecida (la llamada prevención secundaria) y estrategias para identificar a los pacientes de alto riesgo que, aunque sin evidencia clínica de enfermedad vascular arteriosclerótica, son también candidatos para tratamiento médico preventivo.

Dichas guías han servido como referencia en la realización de un consenso adaptado a los condicionantes diferenciales de nuestra realidad médico-social. Además se plantea el abordaje de problemas generales que el rápido aumento en la investigación dedicada a este campo ha traído al ámbito clínico, los factores de riesgo controlados genéticamente y la prolongación de la esperanza de vida de la población. Por tanto, la necesidad y oportunidad de este documento son evidentes. Está claro que no es el definitivo, como está claro que la investigación básica y clínica están continuamente aportando nuevos conocimientos que podrán hacer incluir o eliminar en el futuro ciertos aspectos de esta versión, apta para el año 2000. Pero precisamente en este punto radica la importancia de la ciencia y su evolución como la fuerza motora que ha dirigido y articulado la historia del hombre y su salud. El progreso biomédico es un proceso en continuo desarrollo en beneficio de la salud.

\section{Lina Badimón Maestro}

Presidenta de la Sociedad Española de Arteriosclerosis 


\section{PARTICIPANTES}

\section{Comité organizador}

Ministerio de Sanidad y Consumo.

Subdirección General de Epidemiología, Promoción y Educación para la Salud.

Sociedad Española de Cardiología

Sociedad Española de Arteriosclerosis

\section{Coordinación}

Fernando Villar Álvarez

Ignacio Plaza Pérez

\section{Grupo redactor}

José Ramón Banegas Banegas

José Antonio Casanovas Lenguas

Enrique Gil López

Antonio Maiques Galán

Pedro Mata López

Francisco Pérez Jiménez

Ignacio Plaza Pérez

Fernando Rodríguez Artalejo

Luis Tomás Abadal

Fernando Villar Álvarez

\section{Sociedades científicas e instituciones participantes}

Agencia de Evaluación de Tecnologías

Sanitarias (Instituto de Salud Carlos III)

Asociación de Bioética Fundamental y

Clínica

Asociación de Economía de la Salud

Asociación Española de Biopatología

Médica

Asociación Española de Pediatría
Centro Nacional de Epidemiología

(Instituto de Salud Carlos III)

Dirección General de Atención Primaria

y Especializada (Instituto Nacional de la Salud)

Fundación Española del Corazón

Fundación Española de Nutrición

Sociedad Española de Bioquímica Clínica y Patología Molecular

Sociedad Española de Diabetes

Sociedad Española de Endocrinología y

Nutrición

Sociedad Española de Epidemiología

Sociedad Española de Farmacología Clínica

Sociedad Española de Geriatría y

Gerontología

Sociedad Española de Hipertensión

Sociedad Española de Medicina General

Sociedad Española de Medicina Interna

Sociedad Española de Medicina Rural y Generalista

Sociedad Española de Nutrición

Comunitaria

Sociedad Española de Salud Pública y Administración Sanitaria

Subdirección General de Epidemiología, Promoción y Educación para la Salud (Ministerio de Sanidad y Consumo)

\section{Expertos consultados}

Eduardo Alegría Ezquerra

Javier Aranceta Bartrina

Pedro Aranda Lara

Francisco Arnalich Fernández

Rosario Artigao Ramírez

Ricardo Astorga Jiménez 
Lina Badimón Maestro

Carlos Brotons Cuixart

Rafael Carmena Rodríguez

Conxa Castell Abat

Alfonso Castro Beiras

Felipe Chavida García

Juan Cosín Aguilar

José María Cruz Fernández

Alfonso Delgado Rubio

Roberto Elosua Llanos

Ignacio Ferreira Montero

Blas Gil Extremera

Juan Antonio Gómez Gerique

Luis Ignacio Gómez López

Manuel Gómez Recio

Jesús González Enríquez

Juan Antonio González González

Lydia Gorgojo Jiménez

Rafael Guayta Escolíes

Juan Luis Gutiérrez Fisac

José Luis Herrera Pombo

Rafael Juane Sánchez

Antonio López Farré

Victor López García-Aranda

José Luis López-Sendón Hentschel

Felix Malpartida de Torres

Jusé María Maroto Montero

Jaume Marrugat de la Iglesia

José María Martín Moreno

Luis Masana Marín

José Mataix Verdú

María José Medrano Albero

Olga Moreiras Tuni

Mar Moreno Yangüela
Javier Muñiz García

Manuel Nebot Adell

Vicente Ortún Rubio

Manuel Oya Otero

José Luis Palma Gámiz

Javier Pintó Sala

Leandro Plaza Celemín

José Puzo Foncillas

Jesús del Real Pérez

Juan del Rey Calero

Manuel de los Reyes López

José Luis Rodicio Díaz

Gustavo C. Rodríguez Roca

Juan José Rodríguez Sendín

Emilio Ros Rahola

Juan Rubiés Prat

Carlos Sáenz de la Calzada Campos

Pau Salva Lacombe

Gema Salvador Castell

Susana Sans Menéndez

Andreu Segura Benedicto

Mariano Sentí Clapés

José Ricardo Serra Grima

Lluis Serra Majem

Jesús Torcal Laguna

María José Tormo Díaz

Ricard Tresserras Gaju

Federico Vallés Belsué

Gregorio Varela Mosquera

Clotilde Vázquez Martínez

\section{Asesores}

Ignacio Balaguer Vintró

Valentín Fuster de Carulla 


\section{LA MAGNITUD DEL PROBLEMA EN ESPAÑA}

La hipercolesterolemia es uno de los principales factores de riesgo cardiovascular modificables. Numerosos estudios observacionales han confirmado el papel predictor y la existencia de una relación causal entre la colesterolemia y la cardiopatía coronaria. En las personas que participaron en el Multiple Risk Factor Intervention Trial (MRFIT) se observó una relación continua y gradual (sin umbral para el comienzo de esa relación) entrc colesterolemia y mortalidad por enfermedad coronaria ${ }^{1}$. Asimismo, esta relación se ha observado en poblaciones de distinta índole sociocultural y racial ${ }^{2}$. La reducción de la colesterolemia produce una disminución de la incidencia y mortalidad por cardiopatía isquémica y enfermedad cardiovascular en general ${ }^{3}$.

La prevalencia de hipercolesterolemia en la población española es alta. En personas de 35 a 64 años de edad, el $18 \%$ (18,6\% en los varones y el $17,6 \%$ en las mujeres) tiene una colesterolemia igual o superior a $250 \mathrm{mg} / \mathrm{dl}$ y el $57,8 \%(56,7 \%$ en los varones y el $58,6 \%$ en las mujeres) igual o superior a $200 \mathrm{mg} / \mathrm{dl}^{4}$. En las mujeres se produce un incremento en la prevalencia de hipercolesterolemia con la edad; sin embargo, en los varones no se aprecia este fenómeno.

Otros estudios realizados en España, en áreas geográficas limitadas, obtienen colesterolemias superiores a $200 \mathrm{mg} / \mathrm{dl}$ aproximadamente en el $50 \%$ de los adultos y superiores a $250 \mathrm{mg} / \mathrm{dl}$ en alrededor del $20 \%{ }^{5-12}$.

El estudio Manresa ${ }^{13}$, circunscrito al ámbito laboral, iniciado en 1968 con el seguimiento de una cohorte industrial masculina de esa ciudad, obtuvo una concentración de colesterol sérico relativamente alta (en el $28 \%$ de los trabajadores de 30 a 59 años era $\geq 250 \mathrm{mg} / \mathrm{dl}$ ), mientras que la incidencia y mortalidad por cardiopatía isquémica eran menores de las que se esperaría encontrar de acuerdo con esa colesterolemia.

La colesterolemia se influye por determinantes genéticos ${ }^{14}$ y alimentarios, en especial la ingestión de grasas saturadas y en menor medida de colesterol ${ }^{15-17}$, La dieta de los españoles ha experimentado cambios asociados al desarrollo económico, en particular cierto alejamiento del patrón mediterráneo, considerado saludable ${ }^{18}$. Desde el año $1964-65$, en que España tenía un patrón muy próximo al de la dieta mediterránca, hasta 1990-91 ha habido un aumento del porcentaje de energía aportado por las grasas (del 32\% en 1964-65 al $42 \%$ en 1990-91), fundamentalmente en detrimento de los hidratos de carbono, los cuales han pasado de proporcionar el $53 \%$ de las calorías totales a aportar el $42 \%{ }^{19-2}$

Existe una clara asociación inversa entre las concentraciones plasmáticas de las HDL y el riesgo de enfermedad coronaria ${ }^{23}$. Se ha sugerido que las personas con bajas concentraciones plasmáticas de cHDL tienen un riesgo de cardiopatía isquémica similar al de las personas con concentraciones elevadas de cLDL. Las concentraciones de las HDL pueden ser también el reflejo de otras lipoproteinas aterogénicas, tales como las VLDL. Los mecanismos por los que las HDL proporcionan protección contra el desarrollo de aterosclerosis no están bien definidos. Posiblemente, las HDL protegen directamente la pared vascular por el transporte de colesterol desde la pared arterial al hígado. Otros mecanismos protectores pueden ser: la inhibición de la oxidación de las LDL, la inhibición de moléculas de adhesión celulares y la producción de prostaciclina, un vasodilatador e inhibidor de la agregación plaquetaria ${ }^{24}$.

Los triglicéridos muestran una asociación positiva y fuerte con la cardiopatía isquémica, aunque durante muchos años se ha creído que esta asociación se debía a la existencia de una relación inversa con el cHDL, ya que es muy frecuente que cuando se elevan los triglicéridos baje el cHDL. Sin embargo, estudios recientes demuestran que los triglicéridos son un factor de riesgo coronario independiente, incluso con concentraciones elevadas de cHDL $^{25,26}$.

Por último, la hipercolesterolemia se asocia a otros factores de riesgo cardiovascular4. Los diferentes factores de riesgo interaccionan positivamente, de forma que el riesgo cardiovascular derivado de la exposición simultánea 
a varios de ellos es superior al que cabe esperar por la simple suma del riesgo correspondiente a cada uno de ellos.

\section{Morbimortalidad cardiovascular}

\subsection{Mortalidad}

Las enfermedades del aparato circulatorio son la primera causa de muerte en España, originando casi el $40 \%$ de todas las defunciones. La enfermedad isquémica del corazón y la enfermedad cerebrovascular representan cerca del $60 \%$ de la mortalidad cardiovascular total. Desde mediados de los años setenta se ha producido en España un descenso de las tasas ajustadas por edad de mortalidad por enfermedades del aparato circulatorio y en menor medida las debidas a cardiopatía isquémica ${ }^{27,28}$ Sin embargo, y debido fundamentalmente al envejecimiento de la población, el número de muertes por cardiopatía isquémica está aumen$\operatorname{tando}^{29}$. Por ello, el impacto demográfico, sanitario y social de estas enfermedades aumentará a lo largo de las próximas décadas.

Comparativamente, España presenta una mortalidad coronaria más baja que la mayoría de los países occidentales y una mortalidad cerebrovascular media-baja entre dichos países ${ }^{30}$.

\subsection{Morbilidad}

Se dispone de datos sobre la incidencia de coronariopatías en España, entre otros, a través del proyecto MONICA, del estudio REGICOR y, en el ámbito laboral, el estudio Manresa. La tasa anual, ajustada por edad, de episodios coronarios entre varones de 35 a 64 años en el estudio MONICA-Cataluña fue de 210 por 100.000 , cifra muy inferior a la media de todo el proyecto MONICA, que fue de 434 por 100.000 en el periodo de 1985-94. En las mujeres la tasa fue de 35 por 100.000 , resultando la más baja de todo el MONICA (media de 103 por 100.000$)^{31}$. El estudio REGICOR obtuvo, en el periodo 1990-92, una tasa anual de episodios coronarios de 183 por 100.000 en varones de 35 a 64 años, y de 25 por 100.000 cn las mujeres ${ }^{32}$.

La tendencia de las tasas de morbilidad hospitalaria de las enfermedades del aparato circulatorio, en los últimos años, ha sido de un constante aumento en varones y en mujeres, con un incremento mayor de la enfermedad coronaria que de la cerebrovascular. Igualmente, el MONICA-Cataluña encuentra un aumento anual del $1,8 \%$ en varones y del $2 \%$ en mujeres de la incidencia de enfermedad isquémica del corazón entre 1985 y $1994^{31}$.

\section{Prioridades de intervención}

El control de la hipercolesterolemia es, junto con la erradicación del tabaquismo y el control de la hipertensión arterial, la diabetes, la obesidad y el sedentarismo, una de las principales estrategias para el control de las enfermedades cardiovasculares ${ }^{33}$. Las estrategias de control de estas enfermedades pretenden evitar la implantación de los hábitos y estilos de vida que favorecen la enfermedad (prevención primordial), evitar la aparición de nuevos casos de enfermedad entre personas libres de la misma (prevención primaria) y entre los que ya han sufrido un episodio cardiovascular previo (prevención secundaria). Las acciones concretas a realizar dependen de varios factores: la eficacia de la intervención, el riesgo de enfermar (a mayor riesgo, mayor beneficio de la intervención), los costes de la intervención en relación con sus beneficios y la carga de trabajo para el sistema sanitario ${ }^{34}$. Por todo ello, se han establecido unas prioridades de control de la colesterolemia y del riesgo cardiovascular derivado de la misma ${ }^{35}$. Los grupos de intervención ordenados de mayor a menor prioridad son los siguientes:

1. Pacientes con enfermedad coronaria establecida u otras enfermedades ateroscleróticas.

2. Personas sanas con riesgo alto de desarrollar enfermedad coronaria u otra enfermedad aterosclerótica, porque presentan una combinación de factores de riesgo - entre ellos están la dislipemia (colesterol total y cLDL elevados, cHDL bajo y triglicéridos elevados), el tabaquismo, la elevación de la presión arterial, la elevación de la glucemia y la historia familiar de enfermedad coronaria prematura-o 
porque presentan una elevación muy importante o forma grave de un solo factor de riesgo, como la hipercolesterolemia u otras formas de dislipemia, hipertensión arterial o diabetes.

3. Familiares de primer grado de pacientes con enfermedad coronaria de aparición precoz u otras formas de enfermedad aterosclerótica y de personas sanas con riesgo cardiovascular muy alto.

4. Otras personas a las que se accede en el curso de la práctica clínica habitual.

\section{PREVENCIÓN PRIMARIA DE LAS ENFERMEDADES CARDIO VASCULARES}

\section{Detección de la dislipemia y estimación del riesgo cardiovascular}

La hipercolesterolemia es un factor de riesgo muy importante de la cardiopatía coronaria, sin embargo, es un predictor pobre del riesgo individual de enfermar ${ }^{36}$. Por ello, el cribado basado sólo en la colesterolemia puede, en ocasiones, clasificar erróneamente a personas como si tuvieran un riesgo alto. Además, la hipercolesterolemia, sin otros factores de riesgo, puede no indicar un riesgo cardiovascular suficiente para beneficiarse del tratamiento. Sin embargo, los pacientes con hipercolesterolemia familiar tienen un elevado riesgo de desarrollar enfermedad cardiovascular en ausencia de otros factores de riesgo. La enfermedad cardiovascular es de origen multifactorial, y la hipercolesterolemia debe ser considerada en el contexto de otros factores de riesgo; de ahí la importancia de evaluar el riesgo cardiovascular global ${ }^{37}$.

El riesgo cardiovascular expresa la probabilidad de padecer una enfermedad cardiovascular en un determinado período de tiempo, generalmente 5 ó 10 años. Dentro del concepto de riesgo cardiovascular se incluye la probabilidad de padecer las enfermedades ateroscleróticas más importantes: cardiopatía isquémica, enfermedad cerebrovascular y arteriopatía periférica. Aunque los métodos de predicción del riesgo calculan fundamentalmente el riesgo coronario, éste puede ser una aproximación razonable del riesgo cardiovascular ${ }^{38}$.

Para un abordaje más correcto de la prevención primaria cardiovascular, se requiere una valoración conjunta de los factores de riesgo por medio del cálculo del riesgo cardiovascular $^{35,39}$. En esta estrategia multifactorial, la clasificación de las personas en grupos de riesgo puede realizarse mediante el uso de los perfiles de riesgo cuantitativo ${ }^{38}$ o a través de aproximaciones cualitativas ${ }^{40}$.

El método cuantitativo emplea la tabla de predicción del riesgo cardiovascular del estudio de Framingham ${ }^{38,39}$. Hay que tener en cuenta que esta tabla puede sobrestimar el riesgo absoluto en poblaciones que ticnen un ricsgo bajo de desarrollar la enfermedad, como es el caso de la población española. Las Sociedades Europeas de Cardiología, Aterosclerosis, Hipertensión, Medicina de Familia/General y la Sociedad Internacional de Medicina del Comportamiento recomiendan una simplificación de dicha tabla (asume un cHDL de $39 \mathrm{mg} / \mathrm{dl}$ en varones y 43 $\mathrm{mg} / \mathrm{dl}$ en mujeres), que incluye sólo las variables: edad, sexo, colesterol total, tabaquismo, presión arterial sistólica y diabetes ${ }^{35}$. El método cualitativo emplea clasificaciones más sencillas basadas en el número de factores de riesgo y es el que sigue el National Cholesterol Education Program II (NCEP-II) ${ }^{40}$, que, estando también basadas en el estudio de Framingham, presentan de forma categórica variables que son continuas y cuantitativas.

La estrategia de valoración del riesgo cardiovascular debe realizarse, preferentemente, en la atención primaria ${ }^{41}$. Una vez diagnosticada la hipercolesterolemia u otro de los factores de riesgo, se determinarán el resto de los factores necesarios para el cálculo del riesgo cardiovascular. En función del nivel de riesgo cardiovascular se adoptarán las medidas de seguimiento y tratamiento correspondientes. Los pacientes que ya han padecido una enfermedad cardiovascular tendrán una evaluación y seguimiento específico ${ }^{42}$, que se verá en el capítulo de prevención secundaria. En presencia de una hiperlipemia familiar, se debe hacer una detección selectiva, al menos, en los familiares de primer grado. 
Las personas que no presentan ningún factor de riesgo cardiovascular mayor (tabaquismo, hipertensión arterial, dislipemia o diabetes mellitus), se considera que son de riesgo cardiovascular bajo. Estas personas no en-tran en un pro-grama específico de intervención. Sin embargo, en este grupo de riesgo bajo se producirán casos de enfermedad cardiovascular ${ }^{42}$ y también deben ser objeto de atención. La actuación en estas personas consiste en acciones integradas en el marco de un programa de examen periódico de salud, que incluye vigilancia sobre tabaco, hipertensión arterial, hipercolesterolemia, nutrición, obesidad, diabetes mellitus, actividad física y consumo de alcohol. Los tres primeros factores son priorita-rios para prevenir las enfermedades cardiovasculares en atención primaria ${ }^{42}$.

En las personas asintomáticas de riesgo bajo se reco-mienda prac-ticar una determinación de colesterol to-tal sérico al menos una vez en los varones antes de los 35 años de edad y en las mujeres antes de los 45 años. Después se determinará con una periodicidad de cinco o seis años hasta los 75 años de edad. A las personas mayores de 75 años que nunca se les haya medido el colesterol sérico se recomienda determinárselo una vez, como mínimo43. Se considera hipercolesterolemia límite las concentraciones de colesterol sérico entre 200 y $249 \mathrm{mg} / \mathrm{dl}$, y se considera hipercolesterolemia definida a partir de cifras iguales o superiores a $250 \mathrm{mg} / \mathrm{dl}$, siempre medido el colesterol total sérico en dos ocasiones separadas en el tiempo ${ }^{42-44}$.

\section{Grupos de mayor riesgo cardiovascular}

\subsection{Fumadores}

El tabaco es responsable de más del $50 \%$ de las muertes prevenibles, de las cuales más de la mitad son de origen cardiovascular ${ }^{45,46}$. El efecto nocivo ocurre en hombres y en mujeres, aumentando con la cantidad diaria y la duración del consumo. En el fumador pasivo también aumenta el riesgo de enfermedad coronaria y de otras enfermedades relacionadas con el tabaco ${ }^{47}$. El tabaquismo se asocia fundamentalmente con los fenómenos isquémicos agudos, probablemente porque su meca- nismo de acción sea la trombosis sobreañadida y el vasoespasmo, además de favorecer el desarrollo de la aterosclerosis. Estudios recientes han demostrado que el fumar puros y cigarrillos bajos en nicotina también aumenta el riesgo de cardiopatía isquémica.

\subsection{Hipertensos}

I a hipertensión arterial es un importante factor de riesgo para la enfermedad coronaria, insuficiencia cardiaca, enfermedad cerebrovascular e insuficiencia renal, en hombres y en mujeres. Además, su asociación frecuente con otros factores de riesgo, como la diabetes mellitus, la insulinorresistencia, la dislipemia - la obesidad, aumenta considerablemente el riesgo cardiovascular ${ }^{48}$. Aproximadamente el $40 \%$ de los hipertensos tienen una colesterolemia superior a $240 \mathrm{mg} / \mathrm{d}^{7,49}$. Esta frecuente asociación epidemiológica se debe a las múltiples conexiones etiopatogénicas y fisiopatológicas que, además de incrementar el riesgo cardiovascular del hipertenso, contribuyen a la elevación crónica de la presión arterial ${ }^{50}$. Por ello, la presencia de dislipemia en la persona hipertensa debe ser tratada más activamente.

El tratamiento de la hipertensión arterial reduce el riesgo cardiovascular, pero no lo revierte completamente. El riesgo de enfermedad cerebrovascular y de insuficiencia cardiaca se reduce considerablemente con el tratamiento antihipertensivo; sin embargo, el efecto protector sobre la enfermedad coronaria es más débil ${ }^{5 !}$. Probablemente esto último se deba, en parte, a la limitada duración de los ensayos clínicos con fármacos antihipertensivos, que no ha sido suficiente para demostrar un efecto mayor.

\subsection{Diabéticos}

La diabetes mellitus tipo 1 y tipo 2 tienen un elevado riesgo de desarrollar enfermedad cardiovascular. La enfermedad macrovascular en los diabéticos no ha recibido la misma atención que la enfermedad microvascular; sin embargo, esta complicación mayor, que produce cardiopatía isquémica, arteriopatía periférica e ictus, es la causa más importante de morbimortalidad en la población diabética, especialmente en la diabetes tipo $2^{52}$. 
La dislipemia diabética con moderada hipercolesterolemia e hipertrigliceridemia y concentraciones bajas de cHDL es muy frecuente y conlleva un elevado riesgo cardiovascular $^{53}$. Una situación muy frecuente en la población occidental es la presencia de intolerancia a la glucosa asociada a hipertensión arterial, hipertrigliceridemia, concentraciones bajas de cHDL, obesidad central e hiperinsulinismo. Esto explica el que muchas personas ya presentan enfermedad aterosclerótica cuando se realiza un diagnóstico de diabetes mellitus.

En la diabetes tipo 1 y 2 , un buen control de la glucemia puede mejorar la dislipemia. Si, después de un adecuado control metabólico, persiste la dislipemia, esta se debe tratar activamente $^{44,54}$. Ensayos recientes de prevención secundaria con fármacos hipolipemiantes han demostrado una importante reducción de la mortalidad cardiovascular y total en los diabéticos ${ }^{55}$. Además, la mortalidad cardiovascular en pacientes con diabetes tipo $2 \mathrm{sin}$ infarto de miocardio previo ${ }^{56}$ es similar a la de los no diabéticos con infarto de miocardio previo.

\subsection{Hiperlipemias primarias}

Se definen como aquellas que no son secundarias a factores dietéticos, ambientales o enfermedades subyacentes, y que tienen una agregación familiar. Pueden afectar a un $5 \%$ de la población y aumentan el riesgo de aterosclerosis y enfermedad cardiovascular prematura, pudiendo encontrarse hasta en un $40 \%$ de las personas supervivientes de un infarto de miocardio.

Los trastornos genéticos del metabolismo lipídico más importantes por sus repercusiones en la población española son (véase tabla 1):

a) La hipercolesterolemia familiar heterocigota se manifiesta desde el momento del nacimiento, observándose la presencia de lesiones ateroscleróticas a partir de la adolescencia $^{57}$. Sin un tratamiento adecuado, menos

\section{Tabla 1}

Diagnóstico diferencial de las hiperlipemias primarias.

\begin{tabular}{|c|c|c|c|}
\hline & $\begin{array}{c}\text { Hipercolesterolemia } \\
\text { familiar }\end{array}$ & $\begin{array}{c}\text { Hiperlipemia familiar } \\
\text { rombinada }\end{array}$ & $\begin{array}{c}\text { Hipercolesterole'mia } \\
\text { poligênica }\end{array}$ \\
\hline Prevalencia & $0,2 \%$ & $1-2 \%$ & $3-4 \%$ \\
\hline Tipo de herencia & Dominante monogénica & Dominante & Poligénica \\
\hline Palogenia & Defecto receptor LDL & Desconocida & Desconocida \\
\hline Edad de comienzo & Nacimiento & $\begin{array}{l}\text { Generalmente }>20 \text { años. } \\
\text { También en la niñez }\end{array}$ & Generalmente $>20$ años \\
\hline Colesterolemia (mg/dl) & $\begin{array}{l}\text { Heterocigoto } 300-550 \\
\text { Homocigoto }>600\end{array}$ & $260-350$ & $280-320$ \\
\hline Lipoproteínas & Aumento LDL & $\begin{array}{l}\text { Aumento LDL y/o VLDL. } \\
\text { Descenso HDL }\end{array}$ & Aumento LDL \\
\hline Xantomas & Frecuentes & Poco frecuentes & Ausentes \\
\hline Cardiopatía isquémica & $\begin{array}{l}30-55 \text { años. } \\
\text { Homocigotos }<20 \text { años }\end{array}$ & $45-55$ años & 60 años \\
\hline $\begin{array}{l}\text { Prevalencia en familiares } \\
\text { primer grado }\end{array}$ & $50 \%$ & $50 \%$ & $10-20 \%$ \\
\hline $\begin{array}{l}\text { Asociación con hipertensión } \\
\text { obesidad y/o diabetes }\end{array}$ & No & Sí & Sí \\
\hline
\end{tabular}


del $20 \%$ de los hombres con hipercolesterolemia familiar alcanzan los 70 años de edad, como consecuencia de la muerte por enfermedad coronaria ${ }^{58}$. Por lo tanto, el diagnóstico de hipercolesterolemia familiar es un buen predictor del riesgo de cardiopatía isquémica y puede establecerse en la niñez.

b) La hiperlipemia familiar combinada se manifiesta con elevaciones de las concentraciones plasmáticas de colesterol y triglicéridos, de manera no siempre simultánea y variable a lo largo del tiempo. Habitualmente, las concentraciones de cHDL son bajas. Entre los familiares es frecuente el hallazgo de diferentes fenotipos hiperlipémicos. Estas características y la existencia de antecedentes familiares de enfermedad coronaria prematura constituyen la base del diagnóstico de esta enfermedad. La presencia de hiperlipemia se puede detectar también en la infancia ${ }^{59}$.

c) La hipercolesterolemia poligénica es la forma más común de hipercolesterolemia primaria y se atribuye a la intervención de distintos genes, cada uno con un efecto relativamente pequeño sobre el aumento en las concentraciones de cLDL. Está estrechamente modulada por factores ambientales y los rasgos hereditarios son menos evidentes. Aunque no existen datos de bimodalidad en las concentraciones plasmáticas de colesterol en las familias de los sujetos afectados, la distribución media de las concentraciones de colesterol están más elevadas que en la población norma ${ }^{60}$. Con frecuencia las personas con hipercolesterolemia poligénica tienen historia familiar de enfermedad coronaria prematura y antecedentes familiares de hipercolesterolemia. Las personas jóvenes con hipercolesterolemia poligénica pueden tener las concentraciones de colesterol normales o ligeramente elevadas y la hipercolesterolemia se puede expresar más tardíamente. El diagnóstico debe sospecharse en cualquier persona con cifras de colesterolemia de 280 a $320 \mathrm{mg} / \mathrm{dl}$ y con concentraciones de triglicéridos normales.

\section{Otros grupos de población}

\subsection{Niños}

El proceso aterosclerótico comienza en la niñez y progresa lentamente en la adolescen- cia, pudiendo conducir posteriormente al desarrollo de cardiopatía isquémica. Los factores de riesgo de la aterosclerosis y la cardiopatía isquémica en los adultos (entre ellos la hipercolesterolemia), también actúan en edades jóvenes ${ }^{61}$.

Los niños y adolescentes con colesterolemia elevada tienen mayor probabilidad de presentar una hipercolesterolemia en la edad adulta que la población general. Se debe identificar a los niños y adolescentes, cuya colesterolemia elevada pueda significar un aumento del riesgo cardiovascular $^{62}$. En este sentido, la presencia de una hiperlipemia familiar aumenta el riesgo de desarrollar cardiopatía isquémica prematu$\mathrm{ra}$. Se recomienda determinar la colesterolemia a los niños con historia familiar de enfermedad cardiovascular precoz o cuando uno de los padres tiene una hiperlipemia familiar, y en los niños con obesidad, diabetes u otras patologías que se asocien con trastornos del metabolismo.

Para disminuir la carga de la enfermedad cardiovascular en la edad adulta, se debe recomendar, a todos los niños sanos mayores de tres años, una dieta baja en grasa saturada y colesterol, es decir, una dieta similar a la del adulto, así como fomentar los hábitos de vida sana, en especial la actividad física.

\subsection{Mujeres}

Aunque la enfermedad coronaria se ha considerado tradicionalmente una enfermedad masculina, ésta es también una causa muy importante de mortalidad en las mujeres mayores de 60 años $^{63,64}$. El hecho de que el sexo masculino sea un factor de riesgo para la enfermedad coronaria se ha interpretado como que el riesgo cardiovascular es menor en las mujeres, que los factores de riesgo son menos predictivos en mujeres que en hombres y que, por tanto, las medidas de intervención serían menos efectivas. Sin embargo, estudios de intervención recientes han demostrado que los factores de riesgo para la cardiopatía isquémica y las estrategias para prevenir la enfermedad cardiovascular también son importantes en las mujeres ${ }^{63,65}$.

\subsection{Personas mayores de 65 años}

Este grupo de población está aumentando en España y, siendo en él la incidencia y pre- 
valencia de la cardiopatía isquémica más elevadas, constituye una de las principales causas de muerte. Las personas mayores de 65 años presentan, con frecuencia, colesterolemia elevada y prevalencia más alta de otros factores de riesgo ${ }^{66}$.

Los factores de riesgo cardiovascular mantienen su valor predictivo también en estas edades. Los últimos estudios de intervención en prevención primaria y secundaria han demostrado que una reducción de la colesterolemia (al igual que en poblaciones más jóvenes) disminuye la morbimortalidad cardiovascular, así como la mortalidad total en personas mayores de 65 años.

El médico debería mantener una actitud positiva sobre los potenciales beneficios de la reducción de la colesterolemia en las personas mayores con hipercolesterolemia ${ }^{67}$. La edad, por sí misma, es un factor de riesgo y conlleva una mayor carga de aterosclerosis. Por lo tanto, no se debe excluir de las medidas de intervención a este grupo de población. Únicamente en presencia de dolencias incapacitantes o debilitantes que reducen una expectativa de vida razonable (neoplasias, demencias, enfermedad pulmonar crónica, etc.), el tratamiento de la hipercolesterolemia con fármacos puede no estar indicado. Como en personas más jóvenes, hay que hacer una valoración global del riesgo cardiovascular, tomando en cuenta cada uno de los factores de riesgo asociados. En esta población debemos tener en cuenta que los efectos adversos de la medicación pueden ser más frecuentes, especialmente con el uso de las resinas y en personas tratadas con numerosos fármacos ${ }^{66}$.

\section{Prevención y tratamiento}

\subsection{Dieta y estilos de vida}

Una dieta adecuada y un estilo de vida saludable (no fumar y mantener un nivel de actividad física acorde con la edad y la condición física de la persona) pueden reducir el riesgo de enfermedad coronaria. Por ello, es deseable que la población, en general, adopte dichos hábitos y, en especial, aquellos grupos de personas con mayor riesgo de sufrir aterosclerosis, como son los fumadores, hipercoles- terolémicos, obesos, diabéticos, hipertensos, sedentarios y los familiares de enfermos con cardiopatía isquémica precoz.

\section{Recomendaciones dietéticas}

a.- Población de riesgo bajo:

Los aspectos dictéticos que más aumentan el riesgo de sufrir enfermedad coronaria son el aporte calórico excesivo y el consumo de grasa saturada. La ingestión excesiva de calorías favorece el desarrollo de obesidad y de resistencia a la insulina, lo que conlleva un mayor riesgo de morbimortalidad. Por ello se debe recomendar una dieta equilibrada, con el aporte conveniente de calorías para conseguir un peso adecuado. Un índice fácil, para conocer la situación ponderal de una persona, es el índice de masa corporal (peso en kilogramos dividido por la altura expresada en metros al cuadrado). Se considera adecuado un índice entre 20 y 25 , cuando es superior a 25 se considera sobrepeso y si es superior a 30 se califica de obesidad. Es conveniente establecer una reducción ponderal pactada con el paciente, lo que le ayudará a alcanzar el objetivo propuesto35. Puede ser razonable alcanzar una pérdida semanal de 0,5 $\mathrm{kg}$, para lo que se necesita conseguir un balance energético negativo de $500 \mathrm{kcal} / \mathrm{día}$. Para ello es de especial utilidad el aumento de la actividad física, tal como se comenta posteriormente.

En España se ha consumido secularmente una dieta rica en grasa monoinsaturada debido a un alto consumo de aceite de oliva, dentro del patrón denominado dieta mediterránea. Este estilo de alimentación se caracteriza por una abundancia de los alimentos de origen vegetal, donde una proporción importante de las calorías procede de los cereales y del aceite de oliva. Además, es típico el consumo abundante de frutas, hortalizas y pescado. El resultado final es un consumo de grasa elevado, que está entorno al $40 \%$ del aporte calórico total, pero siempre predominando los ácidos grasos monoinsaturados ${ }^{19}$. De esta forma los objetivos nutricionales para la población española propuestos por la Sociedad Española de Arteriosclerosis y la Sociedad Española de Nutrición Comunitaria ${ }^{69}$ varían entre el 35 y el $30 \%$ de las calorías totales aportadas por las 
grasas en función de que se utilice o no habitualmente aceite de oliva. El consumo de grasas monoinsaturadas puede variar entre un $15 \mathrm{y}$ un $20 \%$, con una ingestión de grasas saturadas inferior al $10 \%$. La ingestión de colesterol debe ser inferior a $300 \mathrm{mg} /$ día. Simultáneamente, se debe aumentar el consumo de hidratos de carbono complejos hasta un 50-55\% del aporte calórico total. Siguiendo la idea de promover la dieta mediterránea en la población española, en la tabla 2 se recogen, modificadas, las recomendaciones dietéticas de la Sociedad Española de Arteriosclerosis ${ }^{68}$ para prevenir la aterosclerosis en la población general. A ello hay que añadir la limitación en el consumo excesivo de sal y de alimentos ricos en carbohidratos simples, en especial si existe sobrepeso.

La riqueza en vegetales de nuestra dieta hace que proporcione un aporte elevado de carbohidratos complejos, fibra, vitaminas, ácido fólico, antioxidantes y minerales. Entre los antioxidantes tienen especial valor la vitamina $\mathrm{C}$, los $\beta$-carotenos, los tocoferoles y los fenoles (polifenoles y flavonoides). El consumo de flavonoides, los fenoles más abundantes en las plantas, se ha relacionado con una menor mortalidad coronaria en estudios de cohortes $^{70}$. Igualmente, en el estudio MONICA se encontró una correlación inversa entrc la concentración plasmática de vitamina $\mathrm{E}$ y la mortalidad por cardiopatía isquémica ${ }^{71}$. También existe evidencia de que la dieta pobre en ácido fólico se asocia a una mayor mortalidad cardiovascular $^{72}$. Una dieta mediterránea puede proporcionar todos estos nutrientes, sin necesidad de su administración farmacológica.

Los beneficios de la dieta mediterránea son múltiples y se han relacionado con su acción sobre las lipoproteínas plasmáticas, ya que su consumo aumenta el cHDL, a la vez que reduce el $\mathrm{cLDL}^{73-75}$. Más recientemente se ha demostrado que los efectos beneficiosos de la dieta mediterránea se extienden a diferentes mecanismos y factores biológicos que están involucrados en el desarrollo de aterosclerosis. Entre ellos está la reducción de la oxidación de las $\mathrm{LDL}^{76}$, la disminución de la adhesión del monocito al endotelio y la atenuación de la proliferación de la célula muscular lisa ${ }^{76,77}$, el descenso de la presión arterial ${ }^{78-80}$ y el incremento de la capacidad fibrinolítica ${ }^{81}$. Estos efectos biológicos permiten considerar la dieta mediterránea como una excelente alternativa para la prevención de la enfermedad coronaria.

La ingestión de alcohol inferior a 30 gramos diarios se ha relacionado con menor riesgo coronario (10-30 g de alcohol diario, equivalentes a 1-3 copas de vino, 1-3 cervezas o 1-3 servicios estándar de bebidas destiladas). De todos modos, al margen de este potencial efecto beneficioso, el consumo de alcohol se asocia a múltiples enfermedades y a trastornos de la conducta de gran importancia social. El consumo de bebidas alcohólicas se relaciona con el desarrollo de cirrosis hepática, de pancreatitis crónica, de distintos tipos de cáncer, de enfermedades del sistema nervioso central, de miocardiopatía y de alteraciones fetales. El consumo excesivo de alcohol es, además, una enfermedad social, siendo responsable de conductas violentas, accidentes de tráfico, sobre todo en personas jóvenes, maltrato en el seno de la familia y ruptura familiar. Dado que la recomendación de un consumo moderado de alcohol puede elevar su consumo en el conjunto de la población, incluyendo el aumento de bebedores excesivos, el profesional sanitario no debe tener una actitud positiva hacia las bebidas alcohólicas ni recomendar públicamente su consumo, aunque puede considerar aceptable, a escala individual, la ingestión de pequeñas cantidades ${ }^{82}$.

\section{b.- Población de riesgo alto:}

Las personas que pertenecen a los grupos de riesgo cardiovascular alto tienen que extremar las medidas dictéticas. Por ello, sobre la base de la dieta antes indicada, deben reforzar los aspectos nutricionales relacionados con su problema específico. Los obesos y diabéticos con sobrepeso deben adoptar una dieta hipocalórica, por lo que limitarán el consumo de alimentos de mayor valor energético. Cuando exista hipertensión arterial se limitará el consumo de sal.

\section{Consumo de tabaco}

Todo fumador tiene un riesgo elevado de sufrir una enfermedad cardiovascular $o$ neoplásica. Por ello se le debe recomendar el abandono de dicho hábito cada vez que acuda 
Tabla 2

Recomendaciones dietéticas para la prevención de la arterosclerosis en la población general

\begin{tabular}{|c|c|c|c|}
\hline Alimentos & Consumo diario & $\begin{array}{l}\text { Consumo moderado } \\
2-3 \text { veces semanales o } \\
\text { diario con moderación }\end{array}$ & $\begin{array}{l}\text { Consumo muy } \\
\text { Esporádico }\end{array}$ \\
\hline Cereales & $\begin{array}{l}\text { *Pan, }{ }^{*} \text { arroz, }{ }^{*} \text { pastas, } \\
\text { maíz, harinas, cereales y } \\
\text { galletas (de preferencia } \\
\text { integrales). }\end{array}$ & $\begin{array}{l}\text { * Pasta italiana con huevo } \\
\text { y *bollería y galletas pre- } \\
\text { paradas con aceite de } \\
\text { oliva o de semilla. }\end{array}$ & $\begin{array}{l}\text { Bollería, croissánt, ensai- } \\
\text { madas, magdalenas, gan- } \\
\text { chitos, galletas y bollería } \\
\text { industrial preparada con } \\
\text { grasas no recomendables. }\end{array}$ \\
\hline $\begin{array}{l}\text { Frutas, hortalizas y } \\
\text { legumbres }\end{array}$ & Todas & $\begin{array}{l}\text { *Aguacates, *aceitunas, } \\
\text { *patatas fritas en aceite } \\
\text { de oliva o de semilla }\end{array}$ & $\begin{array}{l}\text { Patatas chips o patatas o } \\
\text { verduras fritas en aceites } \\
\text { inadecuados. Coco }\end{array}$ \\
\hline Huevos, leches y derivados & $\begin{array}{l}\text { Leche desnatada, yogur y } \\
\text { productos elaborados con } \\
\text { leche desnatada, clara de } \\
\text { huevo }\end{array}$ & $\begin{array}{l}\text { Queso fresco o con bajo } \\
\text { contenido graso, leche y } \\
\text { yogur semidesnatados. } \\
\text { Huevos enteros (un máxi- } \\
\text { mo de tres semanales). }\end{array}$ & $\begin{array}{l}\text { Leche entera. Nata, que- } \\
\text { sos duros y muy grasos, } \\
\text { flanes y cremas. }\end{array}$ \\
\hline Pescado y marisco & $\begin{array}{l}\text { Pescado blanco, * pescado } \\
\text { azul, *atún en conserva, } \\
\text { almejas, chirlas y ostras. }\end{array}$ & $\begin{array}{l}\text { Bacalao salado, *sardinas } \\
\text { y caballa en conserva (en } \\
\text { aceite de oliva), calama- } \\
\text { res, mejillones, gambas, } \\
\text { langostinos y cangrejos. }\end{array}$ & $\begin{array}{l}\text { Huevas, mojama, pesca- } \\
\text { dos fritos en aceites o } \\
\text { grasas no recomendables. }\end{array}$ \\
\hline Carnes & $\begin{array}{l}\text { Carne de conejo, pollo y } \\
\text { pavo sin piel. }\end{array}$ & $\begin{array}{l}\text { Ternera, vaca, buey, cor- } \\
\text { dero, cerdo, jamón (partes } \\
\text { magras), salchichas de } \\
\text { pollo o ternera. }\end{array}$ & $\begin{array}{l}\text { Embutidos, beicon, ham- } \\
\text { burguesas, salchichas, } \\
\text { vísceras, pato, ganso, } \\
\text { patés. }\end{array}$ \\
\hline Grasas y aceites & Aceite de oliva & $\begin{array}{l}\text { Aceites de semillas y } \\
\text { margarinas sin ácidos gra- } \\
\text { sos trans. }\end{array}$ & $\begin{array}{l}\text { Mantequilla, margarinas } \\
\text { sólidas, manteca de cerdo, } \\
\text { tocino, sebo, aceites de } \\
\text { palma y coco. }\end{array}$ \\
\hline Postres & $\begin{array}{l}\text { * Mermelada, *miel, *azú- } \\
\text { car, sorbetes y repostería } \\
\text { casera preparada con } \\
\text { leche descremada }\end{array}$ & $\begin{array}{l}\text { Flan sin huevo, carame- } \\
\text { los, mazapán, turrón, biz- } \\
\text { cochos caseros y dulces } \\
\text { hechos con aceite de oliva } \\
\text { o semilla. }\end{array}$ & $\begin{array}{l}\text { Chocolate y pastelería. } \\
\text { Postres que contienen } \\
\text { leche entera, huevo, nata } \\
\text { y mantequilla. Tartas } \\
\text { comerciales. }\end{array}$ \\
\hline Bebidas & $\begin{array}{l}\text { Agua mineral, refrescos } \\
\text { sin azúcar, zumos natura- } \\
\text { les e infusiones. Café y té } \\
\text { (tres al día). }\end{array}$ & $*$ Refrescos azucarados. & \\
\hline *Frutos secos & $\begin{array}{l}\text { Almendras, avellanas, } \\
\text { castañas, nueces, pipas de } \\
\text { girasol sin sal, dátiles y } \\
\text { ciruelas pasas. }\end{array}$ & Cacahuetes & $\begin{array}{l}\text { Cacahuetes salados, coco } \\
\text { y pipas de girasol saladas. }\end{array}$ \\
\hline Especias y salsas & $\begin{array}{l}\text { Pimienta, mostaza, hier- } \\
\text { bas, sofritos, vinagre y } \\
\text { alioli. }\end{array}$ & Mayonesa y besamel. & $\begin{array}{l}\text { Salsas hechas con mante- } \\
\text { quilla, margarina, leche } \\
\text { entera y grasas animales }\end{array}$ \\
\hline
\end{tabular}

1. Los alimentos señalados con un asterisco, debido a su riqueza calórica, deben limitarse en personas obesas y en los sujetos con hipertrigliceridemia.

2. Los hipertensos deben limitar el consumo de sal y productos que la contenga, en especial conservas, salsas y comidas precocinadas.

3. La carne de pollo y pavo, sin piel, tiene poca grasa. No obstante es preferible que no se consuma a diario y que se sustituya por otros alimentos, como el pescado o las legumbres.

4. No recomendar el consumo de alcohol, aunque sería aceptable su consumo en los adultos que tomasen hasta $30 \mathrm{~g} /$ dia de alcohol (las personas delgadas y las mujeres no deben rebasar los 20 g/día). Sería desaconsejable dicho consumo en los obesos, mujeres embarazadas e hipertrigliceridémicos.

Fuente: Modificado de referencia 68 . 
a la consulta, de modo especial si pertenece a grupos de riesgo alto. Hay que tener en cuenta que el consejo sanitario para dejar de fumar es una intervención de efectividad demostrada en la atención primaria ${ }^{83}$.

La intervención básica recomendada es el consejo sanitario para dejar de fumar ${ }^{84}$. La utilización de los sustitutos de la nicotina (parches, chicles o nebulizador), en especial en las personas con motivación para dejar el hábito y con alta dependencia de la nicotina, incrementa la eficacia de la intervención ${ }^{43}$.

El consejo sanitario para dejar de fumar implica valorar el conocimiento y la actitud del paciente hacia el tabaquismo. Posteriormente, se le informará sobre los perjuicios de dicho hábito para la salud, en especial la cardiopatía isquémica, el cáncer de pulmón y la bronquitis crónica, y se resaltarán los beneficios derivados del abandono para su salud, calidad de vida y economía. Seguidamente, sc lc recomendará firmemente al abandono del tabaco y se valorará su actitud sobre dicho abandono.

Una vez tomada la decisión de abandonar el hábito se recomienda fijar una fecha para tal decisión, dando una serie de consejos claves para que tenga éxito. Entre ellos está la abstinencia total, evitar estar en presencia de otros fumadores, beber zumo o tomar fruta y comer alimentos bajos en calorías, para evitar la ganancia de peso. Se le deberá aportar material suplementario de ayuda (folletos) y ofrecer sustitutos de la nicotina (parches o chicles), si cumple los criterios anteriormente expuestos. Es aconsejable establecer un seguimiento posterior, al menos, a la semana y al mes de la fecha del abandono.

\section{Actividad física}

La actividad física aeróbica tiene efectos beneficiosos sobre el peso corporal, la presión arterial, los lípidos plasmáticos y la sensibilidad a la insulina, pudiendo prevenir el desarrollo de episodios coronarios. Su efecto fundamental sobre el perfil lipídico, consiste en elevar la concentración plasmática del $\mathrm{cHDL}^{85}$ Adicionalmente produce otros efectos saludables, como son los psicológicos y su capacidad para prevenir la osteoporosis ${ }^{86}$. l_a intervención deseable ha de ser individualizada y se basa en recomendar cualquier medida que implique un aumento de la actividad física. Si se consigue que dicha práctica se incluya en la actividad habitual de la vida diaria, aumentarán las posibilidades de que estas medidas tengan éxito. Entre tales prácticas se incluye no utilizar el ascensor, ir andando al trabajo, aparcar a distancia del lugar al que se va y pasear en los ratos de ocio. También se puede recomendar la práctica de ejercicios de tipo aeróbico, como es andar rápido, correr, nadar, practicar bicicleta o tenis, siendo deseable que su práctica sea diaria, o al menos cuatro días por semana.

Estos ejercicios implican un esfuerzo cardiorrespiratorio moderado, pero se debe recomendar en intensidad, cantidad y frecuencia. Andar rápido durante una hora (aproximadamente $5 \mathrm{~km}$ ) produce una pérdida de energía de unas $400 \mathrm{kcal}$, lo que puede permitir perder algo de peso si se hace a diario. La intensidad debe ser la suficiente para mantener las pulsaciones entre el $60 \%$ y el $85 \%$ de la frecuencia cardíaca máxima teórica (220 menos cdad en años) ${ }^{42,83}$. Este grado de actividad es asequible a casi todas las personas, aunque algunas, sobre todo los obesos y sedentarios, deberán alcanzarlo a lo largo de varias semanas o meses. Existe evidencia indicativa de que un mayor grado de actividad física favorecerá una mayor pérdida de peso, por lo que las personas que estén en mejor forma física podrán sustituir el andar por las otras actividades. Cuando la persona haya alcanzado un peso adecuado continuará con la misma actividad física, lo que le ayudará a liberalizar la dieta, manteniendo el peso. La experiencia demuestra que la pérdida de peso es improbable que se mantenga si se vuelve al nivel de sedentarismo previo, por lo que es deseable continuar con la misma actividad. En las personas sin obesidad la actividad física tendrá la utilidad de ayudar a mantener el peso.

\section{Factores psicológicos}

Los factores ambientales o personales que favorecen el estrés son perjudiciales para el sistema cardiovascular. Entre ellos es especialmente importante el trabajo estresante, caracterizado por la alta demanda y presión temporal, junto a un escaso control y capacidad de 
decisión. Este patrón laboral es frecuente en las profesiones de bajo nivel y favorece el desarrollo de hostilidad, aislamiento social y depresión, factores asociados a mayor morbimortalidad coronaria y a peor pronóstico tras sufrir un infarto agudo de miocardio. Además, estos factores emocionales se asocian a hábitos de vida poco saludables, como el consumo de tabaco, sedentarismo, malos hábitos dietéticos, obesidad y consumo excesivo de alcohol. Por todo ello, se debe procurar una aproximación integral a los hábitos de vida saludable, ya que su adecuación requiere potenciar los aspectos psicosociales que garanticen dicho cambio ${ }^{35}$.

\subsection{Tratamiento farmacológico}

Las estatinas (inhibidores de la HMG-CoA reductasa) son los fármacos de elección en el tratamiento de la hipercolesterolemia. En los ensayos clínicos controlados, realizados en prevención primaria con estatinas ${ }^{3,87}$, se ha obtenido una reducción de la morbimortalidad cardiovascular y de la mortalidad total. Son los hipolipemiantes con mayor capacidad para descender el cLDL. También producen, aunque en menor grado, una elevación del cHDL y tienen buena tolerancia. Basándose en los datos recientes, que muestran el beneficio de la reducción del cLDL en las mujeres, las estatinas se consideran también terapia de primera línea en las mujeres posmenopáusicas con hipercolesterolemia ${ }^{65}$.

Las resinas de intercambio iónico y los fibratos son fármacos de segunda elección, siendo útiles en las personas con intolerancia o contraindicación a las estatinas. No obstante, las resinas se pueden considerar el fármaco de elección en los niños con hipercolesterolemia familiar heterocigota. Las rcsinas descienden el cLDL, aunque pueden elevar los triglicéridos y producen con frecuencia intolerancia digestiva. Los fibratos son los hipolipemiantes que más descienden los triglicéridos y más elevan el cHDL, aunque tienen menos efecto descendiendo el cLDL, y se toleran bien.

Las resinas pueden asociarse a las estatinas para potenciar su efecto hipocolesterolemiante. La asociación de fibratos y estatinas puede ser necesaria en pacientes con hipercolesterolemia asociada a hipertrigliceridemia, en los que la monoterapia no logre controlar ambos trastornos. En los pacientes con hipertrigliceridemia predominante se debe iniciar el tratamiento con fibratos ${ }^{88}$, debiendo limitarse el uso de las resinas cuando los triglicéridos superen los $200 \mathrm{mg} / \mathrm{dl}$.

En la tabla 3 se resumen las características principales de los ensayos clínicos en prevención primaria con fármacos hipolipemiantes:

Tabla 3

Características de los principales ensayos clínicos con fármacos hipolipemiantes en prevención primaria.

\begin{tabular}{|c|c|c|c|c|c|c|c|c|}
\hline Estudio & $\begin{array}{c}\text { Fármaco } \\
\text { (dosis diaria) }\end{array}$ & $\begin{array}{c}\text { Colesterolemia } \\
\text { basal } \\
(\mathrm{mg} / \mathrm{dl})\end{array}$ & $\begin{array}{c}\text { Reducción } \\
\text { colesterolemia } \\
\text { (\%) }\end{array}$ & $\begin{array}{c}\text { Riesgo } \\
\text { Placebo* } \\
(\%)\end{array}$ & $\begin{array}{c}\text { Riesgo } \\
\text { tratamiento } \\
(\%)\end{array}$ & $R R R^{*}$ & - $R A R^{*}$ & $N N T^{*}$ \\
\hline $\mathrm{LRC}^{89}$ & $\begin{array}{c}\text { Colestiramina } \\
(24 \mathrm{~g})\end{array}$ & 276 & 10 & 7 & 6,2 & 11 & 0,8 & 125 \\
\hline Helsink ${ }^{90}$ & $\begin{array}{c}\text { Gemfibrozilo } \\
(1.200 \mathrm{mg})\end{array}$ & 272 & 10 & 4,1 & 2,7 & 34 & 1,4 & 71 \\
\hline WOSCOP$^{3}$ & $\begin{array}{l}\text { Pravastatina } \\
(40 \mathrm{mg})\end{array}$ & 272 & 20 & 7,9 & 5,5 & 31 & 2,4 & 42 \\
\hline $\begin{array}{l}\text { AFCAPS/ } \\
\text { TexCAPS } 87\end{array}$ & $\begin{array}{c}\text { Lovastatina } \\
(20-40 \mathrm{mg})\end{array}$ & 228 & 19 & 2,9 & 1,7 & 41 & 1,2 & 86 \\
\hline
\end{tabular}

* Referido a la mortalidad coronaria y al infarto agudo de miocardio no fatal a los 5 años de tratamiento.

$\mathrm{RRR}=$ reducción relativa del riesgo; RAR = reducción absoluta del riesgo; NNT = número necesario de pacientes a tratar para evitar un caso. 
la colestiramina ${ }^{89}$, el gemfibrozilo ${ }^{90}$, la pravastatina $^{3}$ y la lovastatina ${ }^{87}$.

\subsection{Indicación del tratamiento y objetivo terapéutico}

La indicación del tratamiento dietético o farmacológico y el establecimiento del objetivo terapéutico se harán tras la valoración global del paciente, prestando atención a su edad, sexo, riesgo familiar y presencia de otros factores de riesgo cardiovascular.

Las Sociedades Europeas de Cardiología, Aterosclerosis, Hipertensión, Medicina de Familia/General y la Sociedad Internacional de Medicina del Comportamiento ${ }^{35}$ recomiendan que el tratamiento intensivo, incluyendo el uso de fármacos, se debe establecer estimando el riesgo coronario con una tabla de riesgo (véase tabla 4). Dicho tratamiento podrá aplicarse a los pacientes con un riesgo de sufrir un episodio coronario en los próximos 10 años, igual o superior al $20 \%$. Dado el menor ricsgo cardiovascular de la población española en comparación con los países del centro y norte de Europa, para indicar el tratamiento farmacológico no se recomienda realizar la proyección del riesgo a los 60 años de edad, reforzándose, en este caso, las medidas higiénico-dietéticas.

También, pueden emplearse los criterios del NCEP $\cdot \mathrm{II}^{40}$, que recomienda el tratamiento farmacológico cuando el cLDL es igual o mayor a $190 \mathrm{mg} / \mathrm{dl}$ en las personas que presentan menos de dos factores de riesgo, y cuando el cLDL es igual o mayor a $160 \mathrm{mg} / \mathrm{dl}$ en las personas que presentan dos o más factores de riesgo (véase tabla 5).

En presencia de hiperlipemia familiar ${ }^{58} \mathrm{o}$ diabetes mellitus tipo 254 se podría considerar el tratamiento farmacológico cuando el cLDL sea mayor de $130 \mathrm{mg} / \mathrm{dl}$.

La introducción de fármacos, cuando esté indicada, se hará tras un periodo de 3-6 meses de seguimiento, junto con recomendaciones de cambios en la dieta y en cl estilo de vida.

En los pacientes de riesgo alto (riesgo igual o superior al $20 \%$ - tabla 4 - o personas que presentan dos o más factores de riesgo - tabla 5 -) el objetivo terapéutico se establece en un cLDL inferior a $130 \mathrm{mg} / \mathrm{dl}$.

\subsection{Seguimiento}

Las actuaciones para el seguimiento de los pacientes con hipercolesterolemia se fundamentan en los recursos propios del sistema sanitario, la experiencia clínica del médico y la situación personal del paciente.

El paciente debe ser evaluado a los tres y seis meses de iniciar las recomendaciones sobre hábitos saludables de vida; procurando utilizar la visita para reforzar dichos consejos. En los casos en que se inicie un tratamiento farmacológico se vigilará trimestralmente, con objeto de detectar la aparición de efectos no deseables atribuibles a los fármacos y de alcanzar el objetivo terapéutico. Cuando se llegue a la colesterolemia deseable se distanciarán los controles cada 6-12 meses"1.

El contenido de este seguimiento (tabla 6) conlleva la determinación de un perfil lipídico completo, consistente en colesterol total, cHDL y triglicéridos. Con estos datos se calculará el cLDL (véase el capítulo 4). Además, en pacientes con tratamiento farmacológico se determinarán las transaminasas; en caso de mialgias o de asociación de fármacos con riesgo de miopatía hay que añadir la determinación de la CPK.

Es importante conocer la evolución de los otros factores de riesgo no lipídicos, dada la repercusión que tienen al incrementar el riesgo cardiovascular. Por lo tanto, en cada revisión se insistirá en el consejo antitabaco, en caso de tratarse de una persona fumadora, se determinará la presión arterial y, anualmente, se medirá la glucemia. Para conseguir los objetivos de control de la colesterolemia es fundamental valorar adecuadamente el cumplimiento por parte del paciente de las medidas higiénico-dietéticas y farmacológicas.

\subsection{Factores determinantes de la eficiencia del tratamiento}

Una vez demostrada la eficacia en la reducción de los episodios coronarios con los fármacos hipolipemiantes, existen otros factores que tienen influencia en la relación coste-efectividad, como son el riesgo coronario inicial del 
paciente, el porcentaje de reducción del colesterol total y del cLDL, alcanzado con las intervenciones, y el coste económico de éstas.

Cuando el riesgo coronario inicial, previo al tratamiento, sea más elevado, se requerirá tratar a menos enfermos para evitar un episodio de cardiopatía isquémica, con lo que el coste por episodio evitado será menor ${ }^{92}$. En este sentido, cl tratamicnto de los enfermos de riesgo alto (superior al $20 \%$ en los próximos 10 años), según las recomendaciones indicadas por el grupo de Sociedades Europeas35, parece un enfoque razonable de dicha relación coste-efectividad.

El porcentaje de reducción del colesterol total y del cLDL es variable de unos pacientes a otros para las distintas estatinas, fibratos $y$ resinas, por lo que los objetivos terapéuticos se pueden obtener con diferentes moléculas, dosis y coste económico. El coste por cada miligramo de colesterolemia reducido es un aspecto importante en el análisis del costeefectividad del tratamiento y conviene considerarlo a la hora de seleccionar el fármaco.

Los mejores resultados en los ensayos clínicos sobre la reducción de la morbimortalidad cardiovascular se han conseguido cuando se ha dispuesto de un fármaco, como las estatinas, que ha podido reducir la colesterolemia en un $20 \%$. La reducción de la colesterolemia conseguida con las intervenciones farmacológicas determina, junto con el resto de factores señalados, el número necesario de pacientes a tratar para evitar un caso de enfermedad (NNT). De esta forma a mayor reducción de la colesterolemia, con un mismo riesgo inicial, menor NNT y mejor relación coste-efectividad (tabla 3$)^{3,87}$.

\section{PREVENCIÓN SECUNDARIA DE LAS ENFERMEDADES CARDIOVASCULARES}

La cardiopatía isquémica y sus consecuencias, como la insuficiencia cardíaca, son un motivo muy frecuente de consulta e ingreso en nuestros hospitales. La prevención secundaria y la rehabilitación agrupan todas las medidas para disminuir la mortalidad y el riesgo de presentar nuevos episodios clínicos en pacientes con coronariopatía preexistente.
El riesgo de presentar nuevos episodios es mucho mayor en pacientes con cardiopatía isquémica que en la población general, por ello, una vez diagnosticados, ya son personas con un riesgo cardiovascular muy alto. Estudios en pacientes con infarto agudo de miocardio han demostrado que el riesgo de morir es del $50 \%$ en los diez años siguientes, y en el $80 \%$ de los casos la muerte es por reinfarto, con mayor probabilidad en los meses siguientes al episodio agudo. Los pacientes incluidos en los grupos control de los ensayos de prevención secundaria tienen una incidencia aproximada de reinfarto del $6 \%$ anual, comparado con el $1 \%$ en los estudios de prevención primaria ${ }^{93}$. En el estudio de las Lipid Research Clinics (LRC) con un seguimiento de 10 años de los participantes, los pacientes con infarto de miocardio previo tenían 23 veces más riesgo de morir por reinfarto $y$, aproximadamente, seis veces más riesgo de morir por cualquier causa que los que no tenían este antecedente ${ }^{93}$.

Este mayor riesgo en prevención secundaria que en prevención primaria, es lo que determina que los pacientes con enfermedad coronaria establecida u otra enfermedad aterosclerótica constituyan la primera prioridad en la intervención, que deban ser controlados de una manera mucho más rigurosa y que las indicaciones y objetivos terapéuticos sean más exigentes.

Cuando la aparición de la enfermedad es de forma precoz, antes de los 55 años de edad en los varones y de los 65 años en la mujer, suele existir un perfil de riesgo muy alto. Este perfil alto puede ser debido a la elevación moderada de varios factores de riesgo o a la elevación extrema de alguno de ellos, en muchos casos de origen genético.

El manejo de estos pacientes consiste en disminuir dicho perfil de riesgo alto, tratando todos los factores de riesgo susceptibles de ser modificados y consiguiendo unos niveles donde se ha demostrado el máximo beneficio, es decir, el mínimo riesgo. Para la dislipemia y la hipertensión arterial estos niveles se estiman más bajos que en la población general. Además, se deben prescribir fármacos profilácticos que han demostrado disminuir la mortalidad. 


\section{Tabla 4a}

Tabla de riesgo coronario en prevención primaria de las Sociedades Europeas de Cardiología, Aterosclerosis,

Hipertensión, Medicina de Familia/General y la Sociedad Internacional de Medicina del Comportamiento
Varones

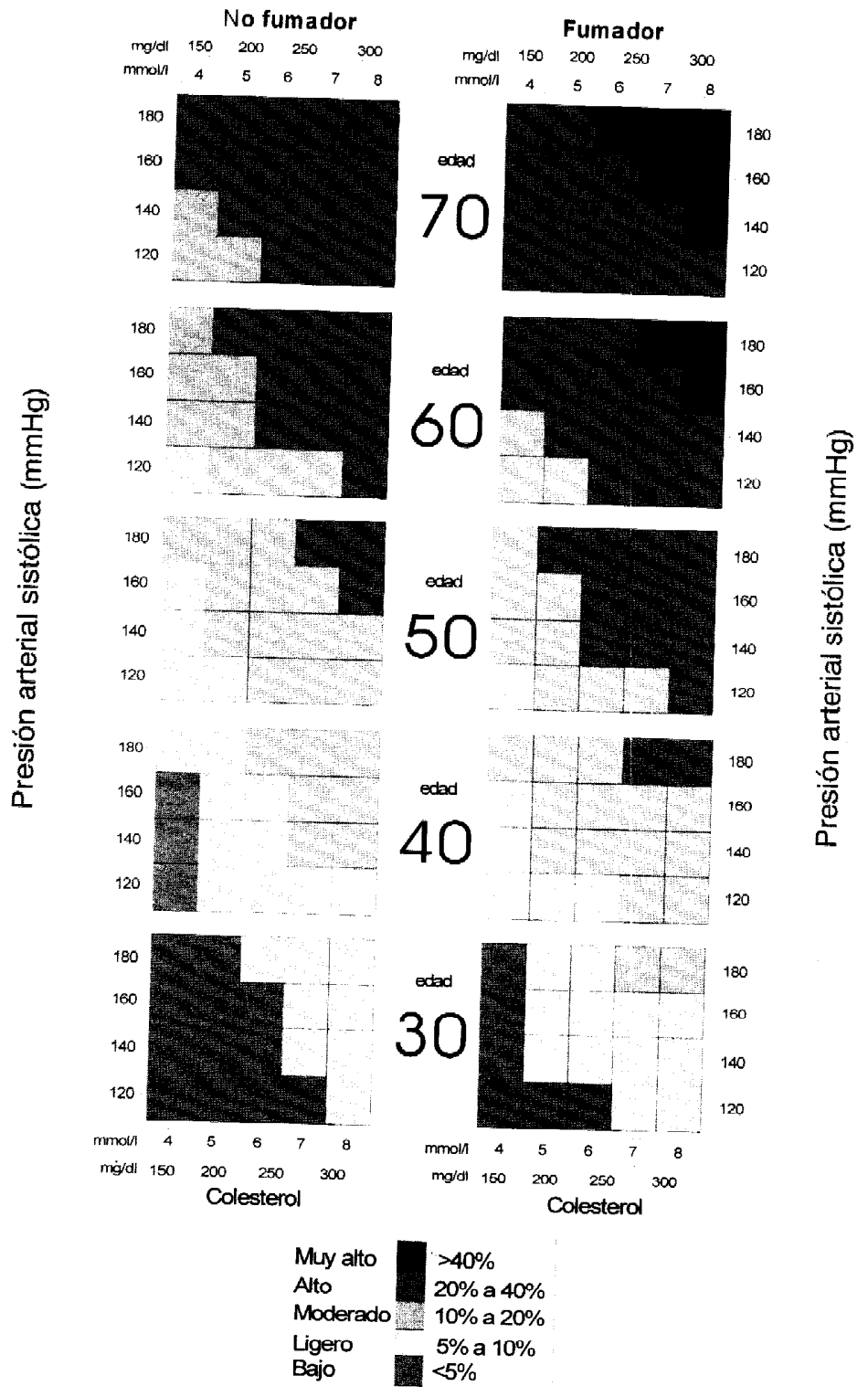

El riesgo coronario es mayor que el indicado en la tabla para las personas que presentan:
- Hiperlipemia familiar.

- Diabetes: el riesgo es aproximadamente el doble en varones y más del doble cn mujeres. (Ver lablas especificas).

- Concentraciones bajes de enfermedad cardiovascular precoz.

- Concentraciones bajas de cHDL. Estas tablas asumen un cHDL de $39 \mathrm{mg} / \mathrm{dl}$ en varones y $43 \mathrm{mg} / \mathrm{dl}$ en mujcres.

- Concentraciones elevadas de triglicéridos (> $180 \mathrm{mg} / \mathrm{dl}$ ).

- Personas cerca de la categoría superior. 


\section{Tabla 2b}

Tabla de riesgo coronario en prevención primaria de las Sociedades Europeas de Cardiología, Aterosclerosis, Hipertensión, Medicina de Familia/General y la Sociedad Internacional de Medicina del Comportamiento ${ }^{4}$.

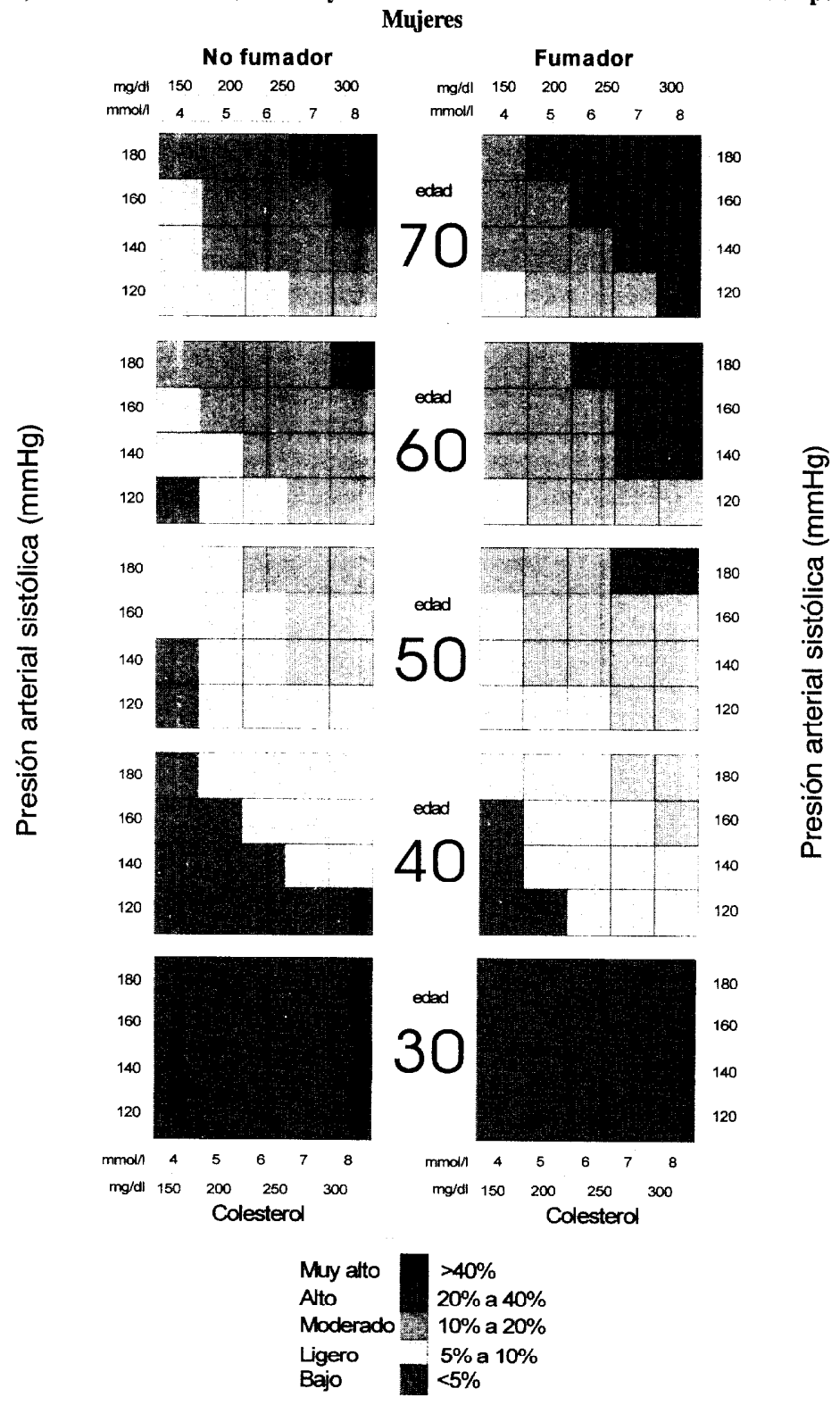

El riesgo coronario es mayor que el indicado en la tabla para las personas que presentan:

- Hiperlipemia familiar.

- Diabetes: el riesgo es aproximadamente el doble en varones y más del doble en mujeres. (Ver tablas específicas).

- Antecedentes familiares de enfermedad cardiovascular precoz.

- Concentraciones bajas de cHDL. Estas tablas asumen un cHDL de $39 \mathrm{mg} / \mathrm{dl}$ en varones y $43 \mathrm{mg} / \mathrm{dl}$ en mujeres.

- Concentraciones elevadas de triglicéridos $(>180 \mathrm{mg} / \mathrm{dl})$.

- Personas cerca de la categoría superior. 
Tabla 2c

Tabla de riesgo coronario en prevención primaria de las Sociedades Europeas de Cardiologia, Aterosclerosis, Hipertensión, Medicina de Familia/General y la Sociedad Internacional de Medicina del Comportamiento ${ }^{4}$.

\section{Varones con diabetes}

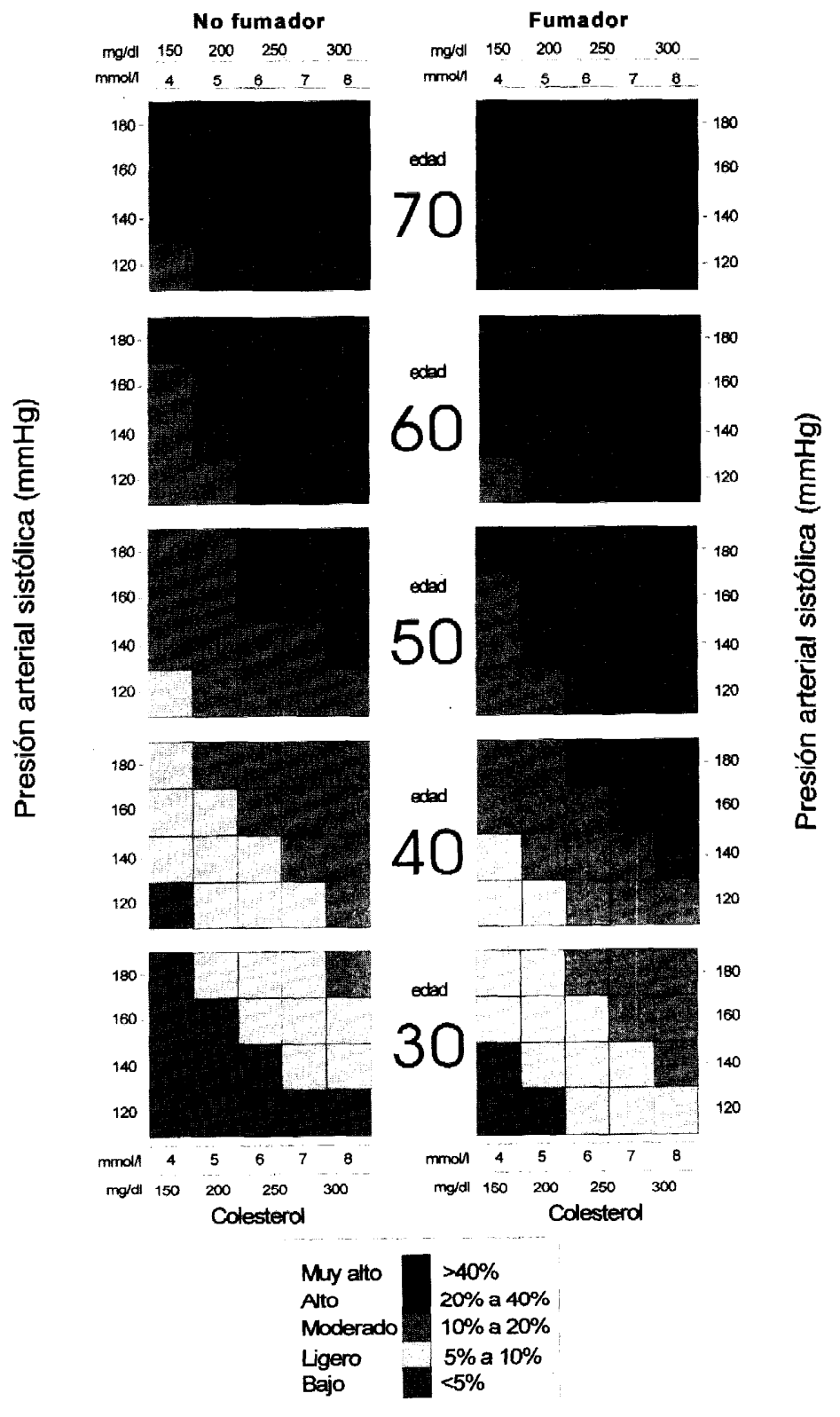

El riesgo coronario es mayor que el indicado en la tabla cuando se da:

- Hiperlipemia familiar.

- Antecedentes familiares de enfermedad cardiovascular precoz.

- Concentraciones bajas de cHDL. Estas tablas asumen un cHDL de $39 \mathrm{mg} / \mathrm{dl}$ en varones y $43 \mathrm{mg} / \mathrm{dl}$ en mujeres.

- Concentraciones elevadas de triglicéridos ( $>180 \mathrm{mg} / \mathrm{dl}$ ).

- Personas cerca de la categoría superior. 
Tabla 4d

Tabla de riesgo coronario en prevención primaria de las Sociedades Europeas de Cardiología, Aterosclerosis, Hipertensión, Medicina de Familia/General y la Sociedad Internacional de Medicina del Comportamiento ${ }^{4}$.

Mujeres con diabetes

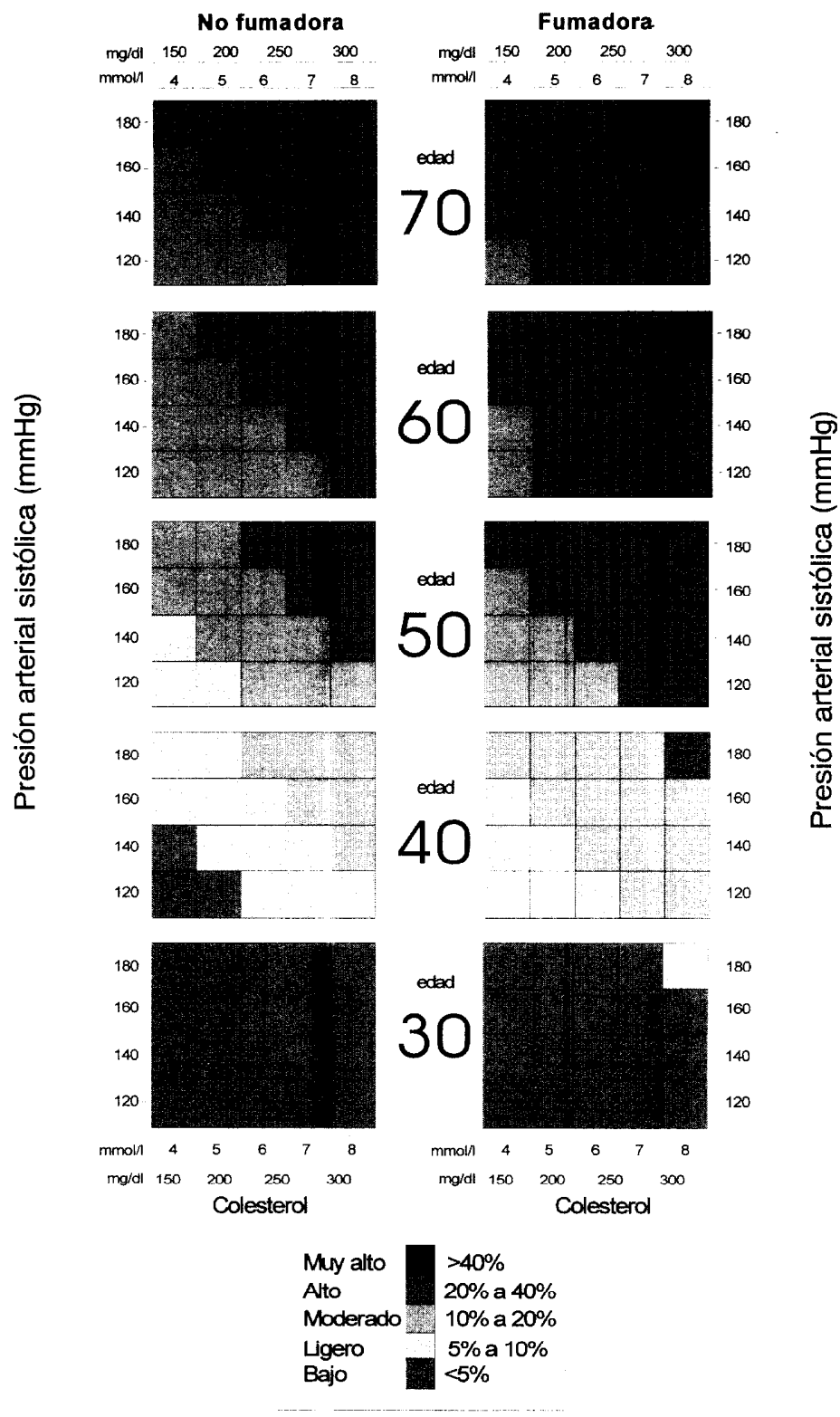

El riesgo coronario es mayor que el indicado en la tabla cuando se da:

- Hiperlipemia familiar.

- Antecedentes familiares de enfermedad cardiovascular precoz.

- Concentraciones bajas de cHDL. Estas tablas asumen un cHDL de $39 \mathrm{mg} / \mathrm{dl}$ en varones y $43 \mathrm{mg} / \mathrm{dl}$ en mujeres.

- Concentraciones elevadas de triglicéridos (>180 mg/dl).

- Personas cerca de la categoría superior. 
Tabla 5

Decisiones de tratamiento en prevención primaria basadas en el cLDL ${ }^{40}$.

\begin{tabular}{|l|c|c|c|}
\hline Riesgo cardiovascular & Objetivo terapéutico & Indicación dieta & Indicación fármacos \\
\hline Menos de dos factores de riesgo & $<160 \mathrm{mg} / \mathrm{dl}$ & $\geq 160 \mathrm{mg} / \mathrm{dl}$ & $\geq 190 \mathrm{mg} / \mathrm{dl}^{*}$ \\
\hline Dos o más factores de riesgo & $<130 \mathrm{mg} / \mathrm{dl}$ & $\geq 130 \mathrm{mg} / \mathrm{dl}$ & $\geq 160 \mathrm{mg} / \mathrm{dl}$ \\
\hline
\end{tabular}

Se consideran factores de riesgo a los siguientes: Edad (en varones $\geq 45$ años, y en las mujeres $\geq 55$ años), tabaquismo, hipertensión arterial ( $\geq 140 / 90 \mathrm{~mm} \mathrm{Hg}$ o empleo de medicación antihipertensiva), diabetes mellitus, cHDL $<35 \mathrm{mg} / \mathrm{dl}$ y antecedentes familiares de enfermedad coronaria precoz (antes de los 55 años de edad en familiares masculinos de primer grado, 0 antes de los 65 años de edad en familiares femeninos de primer grado).

Si la concentración de $\mathrm{cHDL}$ es $\geq 60 \mathrm{mg} / \mathrm{dl}$, se resta un factor de riesgo.

* En los varones de menos de 35 años de edad y en las mujeres premenopáusicas el tratamiento farmacológico se indicará cuando el cLDL sea igual o mayor a $220 \mathrm{mg} / \mathrm{dl}$.

Tabla 6

Actividades de seguimiento en prevención primaria.

1. Determinar el colesterol total, triglicéridos y cHDL y transaminasas. Determinar la CPK en caso de mialgias o de asociación de fármacos con riesgo de miopatía.

2. Aconsejar el abandono del consumo de tabaco en el caso de fumadores.

3. Reforzar las medidas dietéticas y de los estilos de vida.

4. Evaluar el cumplimiento terapéutico.

5. Tomar la presión arterial.

6. Determinar la glucemia anualmente en caso de no diabéticos.

\section{Papel de la dislipemia en prevención secundaria}

La dislipemia es muy frecuente en pacientes con enfermedad cardiovascular. Numerosos estudios anatomo-patológicos, clínicos y de intervención han puesto de manifiesto que la hipercolesterolemia es uno de los factores de riesgo principales para la recurrencia de las enfermedades cardiovasculares, especialmente la cardiopatía isquémica ${ }^{94,95}$.

Los resultados de los estudios de intervención muestran que algunos fármacos, como el clofibrato, son potencialmente peligrosos y otros, como el ácido nicotínico y las resinas, son mal tolerados y pueden interferir con la absorción de otros fármacos, como es el caso de las resinas.
En la década de los 80 aparecen las estatinas, unos fármacos que logran una reducción muy importante de la colesterolemia, comparable a la resección ileal del Program on the Surgical Control of the Hyperlipidemias $(\mathrm{POSCH})^{96}$ de años anteriores y, además, reducen los triglicéridos y aumentan el $\mathrm{cHDL}^{97}$. Lo anterior se traduce en una disminución de la morbilidad y mortalidad cardiovascular y total.

Durante los últimos años de los 80 y primeros de los 90 se diseñan ensayos para valorar el efecto del descenso de la colesterolemia sobre las placas de ateroma de las arterias coronarias. La regresión de dichas placas, se pensaba, aumentaría la luz vascular y, por tanto, el flujo. Los resultados mostraron una regresión de la placa entre un 1-3\% y una menor progresión de la enfermedad. Pero éstos 
resultados no podían explicar todo el beneficio clínico que experimentan los pacientes tratados con estos fármacos, por lo que nacen otros conceptos fisiopatológicos para explicar los beneficios clínicos. Estos son la estabilidad de la placa de ateroma y la mejoría de la función endotelial ${ }^{98,99}$. Por tanto, serían estos mecanismos de acción, junto con el descenso del cLDL, los responsables de los efectos beneficiosos producidos por las estatinas.

En la tabla 7 se resumen las características principales de los ensayos clínicos (Scandinavian Simvastatin Survival Study -4S-100, Cholesterol and Recurrent Events - CARE-101 y Long term Intervention with Pravastatin in Ischaemic Disease - LIPID_- ${ }^{102}$ ) con fármacos hipolipemiantes en prevención secundaria, que han demostrado una reducción de la morbimortalidad coronaria.

El estudio Post Coronary Artery Bypass Graft (Post CABG) ${ }^{103}$ analizó el efecto del tratamiento para disminuir el cLDL sobre la evolución de los puentes aorto-coronarios. Se utilizó lovastatina sola o en asociación con resinas para conseguir el objetivo de cLDL inferior a $100 \mathrm{mg} / \mathrm{dl}$ en el grupo de tratamiento intensivo y de cLDL inferior a $140 \mathrm{mg} / \mathrm{dl}$ en el grupo de tratamiento moderado. A los 4 años de seguimiento la necesidad de revascularización fue un $29 \%$ más baja en el grupo de tratamiento intensivo. El promedio de progresión de la enfermedad fue del $27 \%$ en el grupo de tratamiento agresivo y del $39 \%$ en el de tratamiento moderado, por lo que los autores concluyeron que la progresión de la aterosclerosis en los puentes aorto-coronarios se reduce disminuyendo el cLDL por debajo de $100 \mathrm{mg} / \mathrm{dl}$.

El estudio Atorvastatin versus Revascularization Treatment (AVERT) ${ }^{104}$ mostró, en pacientes con angina estable con tratamiento hipolipemiante intenso (dosis altas de atorvastatina - hasta $80 \mathrm{mg} /$ día-), que el descenso del cLDL hasta $77 \mathrm{mg} / \mathrm{dl}$ era seguro, eficaz y tan efectivo como la revascularización con angioplastia coronaria más el tratamiento habitual, en la reducción de la incidencia de episodios isquémicos.

Un meta-análisis reciente ${ }^{105}$, que incluye 16 ensayos aleatorizados en los que el único tratamiento eran las estatinas, ha mostrado un descenso medio del colesterol total y cLDL del $22 \%$ y $30 \%$, respectivamente, lo que se acompañó de un descenso de la mortalidad total del $22 \%$, que fue atribuido a un descenso de la mortalidad por enfermedades cardiovasculares del $28 \%$ y de la. mortalidad por cardiopatía isquémica del $31 \%$. No se observaron diferencias significativas en los efectos conseguidos entre las diversas estatinas empleadas en estos ensayos, lovastatina, pravastatina y simvastatina. La reducción de la mortalidad total, de la mortalidad por cardiopatía isquémica y por enfermedades cardiovas-

Tabla 7

Características de los principales ensayos clínicos con fármacos hipolipemiantes en prevención primaria.

\begin{tabular}{|l|c|c|c|c|c|c|c|c|}
\hline Estudio & $\begin{array}{c}\text { Fármaco } \\
(\text { dosis diaria })\end{array}$ & $\begin{array}{c}\text { Colesterolemia } \\
\text { basal } \\
(\mathrm{mg} / \mathrm{dl})\end{array}$ & $\begin{array}{c}\text { Reducrión } \\
\text { colesterolemia } \\
(\%)\end{array}$ & $\begin{array}{c}\text { Riesgo } \\
\text { Placebo* } \\
(\%)\end{array}$ & $\begin{array}{c}\text { Riesgo } \\
\text { tratamiento* } \\
(\%)\end{array}$ & RRR* & RAR* & NNT* \\
\hline $4 \mathrm{~S}$ & $\begin{array}{c}\text { Simvastatina } \\
(20-40 \mathrm{mg})\end{array}$ & 261 & 25 & 28 & 19 & 32 & 9 & 11 \\
\hline CARE & $\begin{array}{c}\text { Pravastatina } \\
(40 \mathrm{mg})\end{array}$ & 209 & 20 & 13,2 & 10,2 & 22,7 & 3 & 33 \\
\hline LIPID & $\begin{array}{c}\text { Pravastatina } \\
(40 \mathrm{mg})\end{array}$ & 218 & 18 & 15,9 & 12,3 & 22,6 & 3,6 & 28 \\
\hline
\end{tabular}

* Referido a la mortalidad coronaria y al infarto agudo de miocardio no fatal a los 5 años de tratamiento

$\mathrm{RRR}=$ reducción relativa del riesgo; $\mathrm{RAR}$ = reducción absoluta del riesgo; NNT = número necesario de pacientes a tratar para evitur un caso. 
culares es mayor cuanto mayor es la concentración de cLDL al inicio del tratamiento y el grado de reducción del cLDL alcanzado. La mortalidad no cardiovascular y por cáncer no aumentó con el tratamiento de estatinas.

Un meta-análisis ${ }^{106}$ de ensayos aleatorizados ha valorado la influencia del descenso de la colesterolemia y el tratamiento empleado para conseguirlo sobre la mortalidad por cardiopatía isquémica, la mortalidad no coronaria y la mortalidad total. Este estudio se realizó para separar los efectos del descenso de la colesterolemia por sí misma, de los efectos de los fármacos empleados para conseguirlo. Por cada $10 \%$ de descenso de la colesterolemia se produjo una reducción de un $15 \%$ de la mortalidad por cardiopatía isquémica y de un $11 \%$ de la mortalidad total. Ciertos tipos de tratamiento tienen efectos adversos específicos, dependientes de su mecanismo de acción e independientes del descenso de la colesterolemia que producen. Entre ellos los fibratos (siete ensayos con clofibrato y dos con gemfibrozilo) que, analizados en conjunto, aumentaron la mortalidad no coronaria y la mortalidad total. Si se excluyen los estudios realizados con clofibrato, el aumento de la mortalidad por gemfibrozilo no es significativo. Las hormonas (dos ensayos con estrógenos y dos ensayos con dextrotiroxina) aumentaron la mortalidad por cardiopatía isquémica en hombres, la mortalidad no coronaria y la mortalidad total. El efecto de las estatinas sobre la mortalidad por coronariopatía y la mortalidad total se explica por su capacidad de disminuir los lípidos, y cs directamente proporcional al grado en que los desciende.

Uno de los objetivos en la prevención del riesgo coronario ha sido comprobar si el aumento en las concentraciones plasmáticas de cHDL producía una reducción de la enfermedad coronaria. Recientemente un estudio multicéntrico en varones con cardiopatía isquémica, generalmente mayores de 60 años y con concentraciones bajas de cHDL y cLDL, ha demostrado que la intervención con gemfibrozilo comparada con el placebo disminuyó significativamente el riesgo de morbilidad y mortalidad cardiovascu$\operatorname{lar}^{107}$. El tratamiento con gemfibrozilo aumentó las concentraciones de cHDL, disminuyó las de triglicéridos y no modificó las de cLDL. Este estudio destaca la importancia de la intervención sobre las concentraciones bajas de cHDL. en la reducción del riesgo coronario en pacientes con cardiopatía isquémica.

La publicación de los principales estudios con estatinas, como los estudios 4S, CARE y LIPID, ha tenido un gran impacto en nuestra comunidad científica, produciendo un aumento del interés y conocimiento sobre la prevención secundaria y un cambio de la actitud de los cardiólogos ${ }^{108}$ y otros especialistas españoles en cuanto al tratamiento hipolipemiante. Sin embargo, las encuestas de la Sociedad Española de Cardiología108 sobre intención de tratar y los del estudio de Prevención Secundaria del Infarto de Miocardio (PREVESE) ${ }^{109}$ encuentran todavía un porcentaje elevado de enfermos postinfarto no tratados farmacológicamente, a pesar de ser hipercolesterolémicos.

Un estudio reciente en Estados Unidos ${ }^{110}$ ha puesto de manifiesto que un $8 \%$ de las consultas que se realizan en ese país están relacionadas con el colesterol. No obstante, obtiene que la indicación de analítica y el tratamiento de la hipercolesterolemia se hacen en un porcentaje menor que las recomendadas por las guías terapéuticas, como por ejemplo el documento del NCEP-II ${ }^{40}$. Durante los años 1991 y 1992 en pacientes con cardiopatía isquémica solo al $25 \%$ se les hizo análisis, el $45 \%$ recibió consejos dietéticos y el $39 \%$ estaba con tratamiento farmacológico hipolipemiante.

En el mismo sentido, el European Action on Secundary Prevention through Intervention to Reduce Events (EUROASPIRE) ${ }^{111}$ sobre prevalencia de factores de riesgo a los seis meses del infarto, correspondientes a ocho países europeos, ha observado una elevada prevalencia de factores de riesgo, especialmente de hipercolesterolemia no tratada.

\section{Papel de la dieta en prevención secundaria}

La dieta tiene, junto a otros cambios en el estilo de vida, un importante papel en la prevención secundaria de la cardiopatía isquémica. Hasta el momento, se han realizado seis ensayos clínicos de intervención con dieta 
pobre en grasa en enfermos coronarios, cinco de ellos han obtenido resultados consistentes con el efecto favorable de la intervención dietética. Se utilizó una dieta con aproximadamente el $30 \%$ de aporte graso total, pero modificando la calidad de la grasa administrada con un incremento de la fracción insaturada. En el estudio de la India ${ }^{112}$ se recomendó una dieta rica en fibra, vitaminas antioxidantes y minerales, con un aumento del cociente poliinsaturados/saturados. En el grupo de intervención se redujo el cLDL en un $12 \%$, con un descenso de la mortalidad coronaria en torno al $40 \%$. En el Diet and Reinfarction Trial (DART) ${ }^{113}$ se incrementó el consumo de pescado, y los beneficios se atribuyeron al efecto de los ácidos grasos n3 , por su capacidad de reducir el riesgo trombótico. El descenso relativo de la mortalidad de causa coronaria fue del $29 \%$. En el estudio de Lyon $^{114}$ se administró una dieta mediterránea, enriquecida con aceite de colza, rico en ácido linoléico y oleico, observándose una reducción del $70 \%$ de la morbilidad cardiovascular y del $50 \%$ de la mortalidad total, reafirmando el importante efecto preventivo de la intervención dietética en prevención secundaria. Recientemente, el trabajo del Gruppo Italiano per lo Studio della Sopravvienza nell'Infarto miocardico -Prevenzione (GISSI-P) con una dieta enriquecida con ácidos grasos omega-3, provenientes del pescado, ha demostrado una reducción de la morbilidad cardiovascular del $30 \%$ y de la mortalidad total del $20 \%{ }^{115}$.

En el capítulo de prevención primaria se han indicado los potenciales efectos beneficiosos que tiene la dieta mediterránea sobre distintos factores relacionados con el desarrollo de la aterosclerosis. El conjunto de sus efectos biológicos, unido a la baja tasa de mortalidad en los países mediterráneos, permiten recomendarla a la población española, junto a otros hábitos saludables. Sin embargo, no existe suficiente evidencia para indicar el empleo farmacológico de vitaminas antioxidantes. Además, la dieta mediterránea, rica en frutas y verduras, aporta suficiente cantidad de ácido fólico. Si bien no existen ensayos clínicos que demuestren su eficacia, en las personas de riesgo alto con concentraciones de homocisteina elevadas parece recomendable asegurar la ingestión adecuada de estos nutrientes, me- diante el consumo de suplementos de ácido fólico, vitamina $\mathrm{B} 6$ y vitamina $\mathrm{B} 12^{116}$.

\section{Indicaciones y objetivos terapéuticos en el tratamiento de la dislipemia}

En la fase aguda del infarto agudo de miocardio o tras la cirugía de revascularización coronaria el colesterol total, el cLDL y el cHDL descienden y los triglicéridos se elevan. Estos cambios lipídicos pueden persistir varias semanas. Por ello, se debe hacer la analítica en las primeras 24 horas tras el infarto, que refleja mejor la concentración previa a éste episodio, y otra a los tres meses.

\section{Inicio del tratamiento en pacientes después del infarto agudo de miocardio o cirugía de revascularización}

Las alteraciones metabólicas producidas tras el infarto agudo de miocardio y la cirugía de revascularización crean dudas sobre cuando iniciar el tratamiento hipolipemiante en los pacientes. La dieta baja en grasas saturadas y colesterol debe ser prescrita e instaurada en el hospital a todos los enfermos con cardiopatía isquémica y otras enfermedades cardiovasculares de origen aterosclerótico, independientemente de las concentraciones lipídicas.

Mención especial merece la indicación del tratamiento con fármacos. Conforme con las normas clásicas se debería iniciar el tratamiento farmacológico cuando, una vez normalizadas las alteraciones metabólicas de la fase aguda, se demostrara hipercolesterolemia que no respondiera a la dieta tras un tiempo prudencial, que en estos pacientes no debe ser superior a tres meses ${ }^{40}$. Sin embargo, en algunos pacientes el tratamiento debe instaurarse antes o continuarse durante su ingreso, si se conocía que eran hipercolesterolémicos y estaban ya en tratamiento farmacológico. El tratamiento precoz con estatinas tras un síndrome coronario agudo mejora la función endotelial $^{117}$, reduce los episodios y la mortalidad coronaria, y facilita el cumplimiento terapéutico tras la hospitalización. Por ello, las personas con elevaciones importantes del cLDL y del colesterol total, superiores a 160 y $240 \mathrm{mg} / \mathrm{dl}$ respectivamente, deben recibir tra- 
tamiento farmacológico durante el ingreso hospitalario.

Teniendo en cuenta la evidencia disponible, se formulan las recomendaciones en prevención secundaria para el manejo y tratamiento de la dislipemia, recogidas en las tablas 8 y 9 . En prevención secundaria el tratamiento farmacológi- co se instaurará con un cLDL $\geq 130 \mathrm{mg} / \mathrm{dl}$ y el objetivo terapéutico será cLDL<100 mg/dl.

\section{Control y seguimiento de la dislipemia}

El tratamiento hipolipemiante es un tratamiento a largo plazo, en la mayoría de los pa-

Tabla 8

Indicaciones del tratamiento basadas en el cLDL en prevención secundaria

\begin{tabular}{|l|l|}
\hline cLDL $<100 \mathrm{mg} / \mathrm{dl}$ & Dieta \\
\hline cLDL $100-129 \mathrm{mg} / \mathrm{dl}$, y sin otros factores de riesgo & Dieta \\
\hline$*_{\text {cLDL } 100-129 \mathrm{mg} / \mathrm{dl} \text { con algún factor de riesgo }}$ & Dieta + Fármacos \\
\hline cLDL $\geq 130 \mathrm{mg} / \mathrm{dl}$ & Dieta + Fármacos \\
\hline
\end{tabular}

* Especialmente cllDL bajo y triglicéridos altos, diabéticos y trasplantados.

Tabla 9a

Fármacos hipolipemiantes indicados en prevención secundaria según el tipo de alteración lipídica (cLDL y triglicéridos)

\begin{tabular}{|l|l|}
\hline $\mathrm{cLDL} \geq 130 \mathrm{mg} / \mathrm{dl}$ y Triglicéridos $<200 \mathrm{mg} / \mathrm{dl}$ & $\begin{array}{l}\text { Estatinas } \\
\text { Estatinas + Resinas }\end{array}$ \\
\hline \multirow{2}{*}{$\mathrm{cLDL} \geq 130 \mathrm{mg} / \mathrm{dl}$ y Triglicéridos $200-400 \mathrm{mg} / \mathrm{dl}$} & $\begin{array}{l}\text { Estatinas } \\
\text { Fibratos } \\
\end{array}$ \\
\hline \multirow{2}{*}{$\mathrm{Estatinas}+$ Fibratos } \\
\hline
\end{tabular}

* En éste grupo la elección del fármaco o de la asociación de fármacos dependerá de las concentraciones relativas de cLDL y de triglicéridos. Cuando los triglicéridos estén muy elevados y el cLDL sea moderadamente alto se elegirán los fibratos. Si no se consiguen los objetivos terapéuticos se añadirán las estatinas.

Tabla 9b

Fármacos hipolipemiantes indicados en prevención secundaria según el tipo de alteración lipídica (cHDL, cLDL y triglicéridos)

\begin{tabular}{|l|l|}
\hline $\begin{array}{l}\text { cHDL }<35 \mathrm{mg} / \mathrm{dl} \mathrm{y} \\
\text { cLDL } \geq 130 \mathrm{mg} / \mathrm{dl} \mathrm{y} \\
\text { Triglicéridos }<200 \mathrm{mg} / \mathrm{dl}\end{array}$ & Estatinas \\
\hline $\begin{array}{l}\text { cHDL }<35 \mathrm{mg} / \mathrm{dl} \mathrm{y} \\
\text { cLDL }<130 \mathrm{mg} / \mathrm{dl} \mathrm{y} \\
\text { Triglicéridos }>400 \mathrm{mg} / \mathrm{dl}\end{array}$ & Fibratos \\
\hline $\begin{array}{l}\mathrm{cHDL}<35 \mathrm{mg} / \mathrm{dl} \mathrm{y} \\
\text { cLDL }<130 \mathrm{mg} / \mathrm{dl} \mathrm{y}\end{array}$ & \\
Triglicéridos $<200 \mathrm{mg} / \mathrm{dl}$ & Fibratos \\
\hline
\end{tabular}


Tabla 10

Manejo de la dislipemia en el paciente con síndrome coronario agudo.

$1^{\text {er }}$ Análisis (ingreso hospitalario). Determinar el colesterol total, triglicéridos y cHDL en las primeras 24 horas tras el episodio coronario agudo, en ayunas de 12 horas. Calcular el cLDL por la fórmula de Friedewald. Si no se hace lo anterior, por lo menos hacer colesterol total.

- Si cLDL $\leq 100 \mathrm{mg} / \mathrm{dl}$ : Dieta y consejos sobre estilo de vida.

- Si cLDL $>100 \mathrm{mg} / \mathrm{dl}$ : Dieta y consejos sobre estilo de vida. Estudio de las causas de la dislipemia. Si el paciente era hipercolesterolémico conocido con tratamiento farmacológico debc continuarlo. Si el cLDL es superior a $160 \mathrm{mg} / \mathrm{dl}$ también se deben indicar fármacos. Si se ha hecho colesterol total sólo, indicar tratamiento farmacológico si es superior a $240 \mathrm{mg} / \mathrm{dl}$, y medidas higiénico-dietéticas si está entre $200-240 \mathrm{mg} / \mathrm{dl}$.

$2^{\circ}$ Análisis (a los 3 meses). Repetir análisis de colesterol total, triglicéridos y cHDL en ayunas de 12 horas.

- Si cLDL $\leq 100 \mathrm{mg} / \mathrm{dl}$ en esta y en la determinación anterior: Dieta y consejos sobre estilo de vida. Análisis al año.

- Si cLDL $>100 \mathrm{mg} / \mathrm{dl}$ en esta y en la determinación anterior: Iniciar el tratamicnto scgún Tablas 8 y 9 y citar para la próxima consulta a los 6 meses. Si es una cardiopatía isquémica precoz o hipercolesterolemia familiar grave citar también a los hijos.

3er Análisis (a los 6 meses). Determinar el colesterol total, triglicéridos y cHDL para comprobar si se ha logrado el control de la dislipemia. Si está en tratamiento farmacológico pedir enzimas hepáticos y en caso de mialgias CPK.

- Si cLDL $\leq 100 \mathrm{mg} / \mathrm{dl}$ el objetivo terapéutico está cumplido.

- Si cLDL > $100 \mathrm{mg} / \mathrm{dl}$ aumentar el tratamiento.

$4^{\circ}$ y $5^{\circ}$ Análisis. Si en los análisis anteriores estaba controlado el cLDL entonces se podría determinar sólo el colesterol total y los triglicéridos. Si está en tratamiento farmacológico pedir enzimas hepáticos y en caso de mialgias $\mathrm{CPK}$.

\section{SEGUNDO AÑO Y SUCESIVOS}

Visitas cada 6 meses con la sistemática de las visitas del $4^{\circ}$ y $5^{\circ}$ análisis. Sería conveniente determinar el colesterol total, triglicéridos y cHDL para calcular el cLDL anualmente.

cientes es de por vida. Por ello, es tan importante indicarlo como mantenerlo, asegurando el cumplimiento por parte del enfermo y vigilando los objetivos terapéuticos y los posibles efectos secundarios. La estrategia propuesta para el manejo de la dislipemia en prevención secundaria se recoge en la tabla 10.

\section{Programas de prevención secundaria}

Los programas de prevención secundaria agrupan todas las medidas tendentes a dis- minuir la mortalidad y el riesgo de presentar nuevos episodios isquémicos en los pacientes con enfermedad coronaria establecida $u$ otra enfermedad aterosclerótica. La utilidad de estos programas se ha demostrado en numerosas publicaciones de las últimas décadas $^{118}$.

La complejidad de la enfermedad cardiovascular y la necesidad de controlar los factores de riesgo con un nivel de exigencia elevado aconsejan que los pacientes con cardiopatía isquémica y otras enfermedades cardiovascu- 
lares sean tratados en el marco de programas de prevención secundaria y rehabilitación, que han sido recomendados por la Sociedad Española de Cardiología ${ }^{19,120}$.

\subsection{Indicaciones del programa de prevención secundaria}

El programa está indicado en las personas que tengan manifestaciones de cardiopatía isquémica por primera vez, con independencia de su edad y de acuerdo con sus necesidades individuales. Los pacientes con las siguientes manifestaciones clínicas pueden ser seleccionados: Angina estable, síndromes coronarios agudos, angina inestable, infarto sin onda Q e infarto transmural. También estará indicado en pacientes revascularizados mediante cirugía o angioplastia coronaria.

Las características de cada paciente determinarán el tiempo y el contenido del programa, el cual debe adaptarse a las peculiaridades individuales del enfermo. 'Todos los programas, aunque diseñados individualmente, tienen en común la reducción de la progresión de la enfermedad y la aparición de sus complicaciones. El cómo realizarlo dependerá de las circunstancias individuales.

Siempre que sea posible se deben controlar los factores de riesgo, como la dislipemia y la hipertensión arterial, y modificar el estilo de vida, abandonando el consumo de tabaco antes de realizar procedimientos de revascularización.

Las personas incluidas en el programa de cardiología preventiva y rehabilitación cardíaca que han dejado de fumar, pierden peso, consiguen una forma física adecuada, controlan la hipertensión arterial y las concentraciones de lípidos, tienen menos probabilidades de sufrir complicaciones perioperatorias en la cirugía cardíaca y de sobrevivir cuando éstas ocurren. Después de la cirugía y de la angioplastia coronaria transluminal percutánea, los programas deben considerar los aspectos físicos con la máxima atención para conseguir la reincorporación social y laboral lo antes posible.

\subsection{Contenido de los programas}

La organización de los programas variará dependiendo de las necesidades y de los recur- sos disponibles; sin embargo, los principales componentes de los mismos deberían de poder llevarse a cabo en todos los centros. Los tres pilares fundamentales son: el control de los factores de riesgo, el entrenamiento físico supervisado y el tratamiento psicológico.

- Valoración y control del perfil de riesgo y del estilo de vida del paciente

La valoración de los factores de riesgo cardiovascular es esencial para adaptar el programa a las necesidades individuales. La promoción de un estilo de vida saludable es la base sobre la que se sustenta el programa.

- Ejercicio físico y estilo de vida activo

El entrenamiento físico programado durante dos o tres meses en el marco de un programa de prevención ha demostrado ser beneficioso, disminuyendo la mortalidad y mejorando la calidad de vida. En muchos pacientes el miedo a la repetición de los síntomas les conduce a una vida sedentaria. Los programas de rehabilitación cardíaca han demostrado que la mejoría en la capacidad funcional va pareja a un aumento en la autoconfianza y en el enfoque más optimista de su situación. El mantener una actividad física de manera permanente es una parte importante de éstos programas y la pueden llevar a cabo los pacientes de riesgo bajo en centros polideportivos o en gimnasios, donde estén cubiertas las necesidades básicas de atención médica a estos enfermos.

- Medidas a tomar por el resto de la familia

Para que el paciente pueda conseguir y mantener un estilo de vida saludable es necesario que las personas que convivan con él se impliquen. Para el paciente es más fácil dejar el tabaco si su familia no fuma y el ambiente de la casa está libre de tabaco. Los cambios dietéticos son más fáciles de hacer si la persona que compra y cocina está involucrada en el programa y toda la familia adopta el mismo tipo de alimentación. Igualmente, para que el enfermo tenga mayor actividad física es conveniente el apoyo de la familia, practicando esta actividad durante el tiempo libre. 
Los cambios en el estado de ánimo son relativamente frecuentes y requieren un tratamiento especializado, pero los familiares deben conocer su existencia y la necesidad de apoyar al enfermo para superarlos. Las relaciones sexuales plantean frecuentemente problemas en estos pacientes y deben ser manejados por personal experto.

- Estudio de los familiares de primer grado

Se deben estudiar los factores de riesgo de los familiares de primer grado de los pacientes con enfermedad cardiovascular prematura, por su mayor propensión a padecer la enfermedad.

\section{- Apoyo psicológico}

La personalidad y el estrés influyen en la enfermedad. Además, las respuestas emocionales anormales tras padecerla, como la ansiedad o la depresión, requieren tratamiento específico y constituyen una parte importante del programa. El cambio del estilo de vida, que es necesario hacer en un porcentaje significativo de pacientes, requiere el apoyo de especialistas en este campo.

\section{Cambios en el comportamiento}

El médico y el paciente deben trabajar conjuntamente en el estadio de preparación y consejos al paciente para que cambie, en el estadio de cambio propiamente dicho, que requiere poner en marcha las iniciativas por parte del enfermo y una atención y control estrecho por parte del médico, y en el estadio de mantenimiento en el que se adoptarán las medidas necesarias para que los cambios se mantengan en el tiempo.

El paciente y el médico deben pactar cómo llevar a cabo los cambios requeridos. No hay un tiempo preestablecido para cada estadio y éste debe ajustarse a cada caso individualmente. La información debe ser clara, concreta y adaptada al nivel de entendimiento de cada paciente. Se deben evitar los términos técnicos $y$, cuando sea posible, se debe reforzar con folletos y material audiovisual.

\subsection{Descripción del programa}

A. Modificación del estilo de vida
1. Dejar de fumar completamente.

2. La dieta debe ser pobre en grasa saturada ( $<10 \%$ del aporte calórico total) y en colesterol ( $<300 \mathrm{mg} /$ día), tal como previamente se ha comentado. Se puede aceptar un consumo total de grasa elevado (hasta el $35 \%$ del aporte calórico), siempre que sea a expensas de grasa procedente del aceite de oliva, dentro del característico patrón de la dieta mediterránea. Asimismo, se tendrá en cuenta la necesidad de controlar el aporte calórico total para evitar el sobrepeso, moderar el consumo de bebidas alcohólicas y limitar la sal cuando exista hipertensión arterial.

3. Llevar a cabo una actividad física regular y de acuerdo con las pautas marcadas por los resultados de la prueba de esfuerzo, que previamente debe hacer todo paciente.

\section{B. Control de los factores de riesgo}

Para mejorar el perfil de riesgo, es necesario conseguir en este grupo unos niveles más bajos en los factores de riesgo que en la población sana, para lo cual, además de la modificación del estilo de vida, es necesario en muchas ocasiones añadir fármacos.

\section{Lípidos}

El objetivo terapéutico es que el cLDL sea igual o inferior a $100 \mathrm{mg} / \mathrm{dl}$ y el colesterol total inferior a $200 \mathrm{mg} / \mathrm{dl}$ y modificar el cHDL y los triglicéridos lo más favorablemente posible. Esto se hace primero con dieta y si no es suficiente, como ocurre en la mayoría de los casos, es necesario añadir fármacos, esencialmente estatinas, conforme a lo señalado en las tablas 8 y 9 .

\section{Presión arterial}

Si la presión arterial es igual o superior a 140/90 mm Hg, se debe reducir esta mediante medidas higiénico-dietéticas primero $y$, si no se consigue, se deben prescribir fármacos 121 . En pacientes postinfarto los fármacos de primera elección son los betabloqueantes y los IECA. En pacientes con angina están indicados los betabloqueantes y los antagonistas del calcio. En pacientes con disfunción ven- 
tricular e insuficiencia cardíaca son de elección los IECA, los diuréticos y los betabloqueantes.

\section{Obesidad}

Cuando el índice de masa corporal es mayor de $25 \mathrm{~kg} / \mathrm{m} 2$ hay que reducir el peso con una dieta adecuada y la realización de una actividad física regular, lo que se traducirá en un descenso del colesterol total y cLDL, de la presión arterial, aumento del cHDL y mejora de la resistencia insulínica y del metabolismo de la glucosa.

\section{Diabetes}

En los pacientes diabéticos hay que extremar el control de la glucemia. La dieta pobre en grasas saturadas y colesterol y la actividad física son necesarias en estos pacientes. El control riguroso del resto de los factores de riesgo cardiovascular es esencial para reducir el riesgo elevado que tienen estos pacientes.

\section{Prescripción de fármacos profilácticos}

Algunos fármacos han demostrado reducir la morbilidad y mortalidad cardiovascular y total en prevención secundaria, por ello están indicados en éstos pacientes. La dosis empleada, siempre que sea posible, debe ser la misma que ha demostrado eficacia en los ensayos clínicos.

a. El ácido acetilsalicílico a pequeñas dosis, $75-200 \mathrm{mg} /$ día, está indicado en prácticamente todos los enfermos de cardiopatía isquémica y en algunas otras enfermedades ateroscleróticas.

b. Los betabloqueantes están indicados en los pacientes con angina e infarto de miocardio y disfunción ventricular y en pacientes con ciertas arrítmias auriculares y ventriculares.

c. Los IECA están indicados en pacientes con infarto agudo de miocardio y signos de insuficiencia cardíaca o con disfunción sistólica persistente.

d. Los anticoagulantes son necesarios en los pacientes post infarto agudo de miocardio con riesgo alto de embolismo sistémico.

\section{Estudio de los familiares de primer grado de los pacientes}

A los familiares de primer grado de los pacientes con enfermedad cardiovascular prematura (varones antes de los 55 años y mujeres antes de los 65 años), debido a su mayor propensión a padecer la enfermedad, se les debe estudiar los factores de riesgo una vez detectado el caso. Si los familiares de primer grado son niños, se les puede hacer el estudio de la presión arterial, lipemia y glucemia al final de la adolescencia, excepto si se sospecha la existencia de hipercolesterolemia familiar, en cuyo caso se debe hacer cuanto antes.

\subsection{Resultados de los programas de prevención secundaria y rehabilitación}

Los programas de prevención secundaria y rehabilifación cardíaca reducen la mortalidad total y a morbilidad y mortalidad coronaria y cardiovascular de forma significativa. Si a ello unimos los resultados sobre reincorporación lahoral, $85 \%$ de las personas rehabilitadas frente al $30 \%$ de los que siguen las medidas habituales, tendremos que concluir que la razón coste-efectividad de los programas de prevención y rehabilitación cardíaca es hoy la más favorable de todos los tratamientos y medidas intervencionistas que se practican en enfermos cardíacos ${ }^{122,123}$.

Con el fin de obtener el máximo beneficio para el paciente con el menor gasto sanitario, cada vez se impone con más fuerza el concepto global dentro de la prevención secundaria, que debe abarcar los programas de ejercicio protocolizados y el control riguroso de los principales factores de riesgo. Igualmente, la atención del enfermo con cardiopatía isquémica debe ser global y abarcar tanto el aspecto clínico como el preventivo ${ }^{118}$.

\section{FIABILIDAD DE LA DETERMINACIÓN DE LACOLESTEROLEMIA}

La medición de la colesterolemia está sujeta a variaciones biológicas y de laboratorio, que pueden redundar en una clasificación inadecuada del riesgo individual. La elección de un labo- 
ratorio es un tema importante, debido a que existe una amplia variabilidad en la precisión con la que los laboratorios miden la colesterolemia. Además del error analítico del laboratorio clínico, existe un gran número de factores que pueden afectar la determinación de los lípidos plasmáticos y que deben valorarse para obtener una información adecuada del estado de riesgo en el individuo ${ }^{40,124,125}$. Por lo tanto, es preciso establecer una serie de recomendaciones:

- Se deben utilizar métodos enzimáticos automatizados para la determinación del colesterol total, triglicéridos y cHDL. Las determinaciones analíticas de los laboratorios clínicos deberían tener un coeficiente de variación dentro del $3 \%$ en el colesterol total y del $5 \%$ en el cHDL y triglicéridos. Es importante que los procedimientos de laboratorio estén incluidos en un programa de control de calidad con controles internos y externos.

- El cLDL se calcula mediante la fórmula de Friedewald-Fredrickson, siempre y cuando las concentraciones de triglicéridos estén por debajo de $400 \mathrm{mg} / \mathrm{dl}$.

$$
\mathrm{cLDL}=\mathrm{CT}-(\mathrm{cHDL}+\mathrm{TG} / 5)
$$

- Los lípidos deben medirse en un estado metabólico estable, y no se debe modificar de manera significativa la dieta y el peso durante las dos semanas anteriores a la determinación. En caso de existir un proceso agudo y/o grave, debe retrasarse la determinación analítica, al menos seis semanas. En pacientes que han tenido un infarto agudo de miocardio u otro proceso coronario agudo, las concentraciones de lipoproteínas pueden medirse dentro de las primeras 24 horas después del infarto.

- Las determinaciones deben repetirse en el plazo de dos a ocho semanas antes de tomar decisiones terapéuticas.

- Para la determinación de triglicéridos y cHDL la extracción debe hacerse, al menos, con 12 horas de ayuno.

\section{BIBLIOGRAFÍA}

1. Multiple Risk Factor Intervention Trial Group. Multiple risk factor intervention trial. Risk fac- tor changes and mortality results. JAMA 1982; 248:1465-1477.

2. Simons LA. Interrelations of lipids and lipoproteins with coronary artery disease mortality in 19 countries. Am J Cardiol 1986;57:5 G-10G.

3. Shepherd J, Cobe S, Ford I, Isles C, Ross A, Macfarlane $\mathrm{P}$, et al. Prevention of coronary heart disease with pravastatin in men with hypercholesterolemia. N Engl J Med 1995; 333:1301-1307.

4. Bancgas Banegas JR, Villar Álvarez F, Pérez Andrés C, Jiménez García-Pascual R, Gil López E, Muñiz García J, et al. Estudio epidemiológico de los factores de riesgo cardiovascular en la población española de 35 a 64 años. Rev Sanid Hig Publica 1993;67:419-445.

5. The WHO MONICA Project. A worldwide monitoring system for cardiovascular diseases: cardiovascular mortality and risk factors in selected communities. World Health Stat Annu 1989;27-149.

6. Muñiz J, Juane R, Hervada J, López Rodríguez I. Castro Beiras A. Concentraciones séricas de colesterol en la población gallega de 40-69 años de edad. Clin Invest Arterioscl 1991; 3:143-148.

7. Aranda P, Villar J. Estudio epidemiológico andaluz sobre factores de riesgo vascular. Estudio $\mathrm{Al}$ Andalus 90. Sevilla: Consejería de Salud, 1993.

8. Rodríguez JC, Calonge S, Bichara G. Prevalencia de los factores de riesgo de cardiopatía isquémica en la isla de Lanzarote. Med Clin (Barc) 1993;101:45-50.

9. Tormo Díaz MJ, Navarro Sánchez C, Chirlaque López MD, Pérez Flores D. Factores de riesgo cardiovascular en la región de Murcia, España. Rev Esp Salud Pública 1997;71:515-529.

10. Masía R, Pena A, Marrugat J, Sala J, Pavesi M, Covas, et al. High prevalence of cardiovascular risk factors in Gerona, Spain, a province with low myocardial infarction incidence. J Epidemiol Community Health 1998;52:707-715.

11. García Closas R, Serra Majem L, Chacón Castro P, Olmos Castellvell M, Ribas Barba L, Salleras L. Distribución de la concentración de lípidos séricos en una muestra representativa de la población adulta de Cataluña. Med Clin (Barc) 1999;113:6-12.

12. Segura Fragoso A, Rius Mery G. Factores de riesgo cardiovascular en una población rural 
de Castilla-La Mancha. Rev Esp Cardiol 1999; $52: 577-588$

13. Tomás-Abadal L, Varas-Lorenzo C, BernadesBernat E, Balaguer-Vintró l. Coronary risk factors and a 20 -year incidence of coronary heart disease and mortality in a Mediterrancan industrial population. Eur Heart J 1994;15: 1028-1036.

14. López Miranda J, Ordovás JM, Pérez Jiménez $\Gamma$. Interacción genes-dieta como determinanle de las concentraciones plasmáticas de colesterol. Med Clin (Barc) 1998;111:546-551.

15. Keys A, Anderson JT, Grande F. Prediction of serum cholesterol responses of man to changes in fats in the diet. Lancet 1957;2:959-966.

16. Keys A, Anderson JT, Grande F. Serum cholesterol response to changes in the diet, IV. Particular saturated fatty acids in the diet. Mctabolism 1965;14:776-787.

17. Hegsted DM, McGandy RB, Myers ML, Stare FJ. Quantitative effects of dietary fat on serum cholesterol in man. Am J Clin Nutr 1965;17: 281-295.

18. Ros Rahola E, Fisac C, Pérez-Heras A. ¿Qué es realmente la dieta mediterránea? FMC 1998;5:557-571.

19. Varela G, Moreiras O, Carbajal A, Campo M. Estudio Nacional de Nutrición y Alimentación 1991. Tomo I. Encuesta de Presupuestos Familiares 1990-91. Ma-drid: Ins-tituto Nacional de Estadística; 1995.

20. Serra-Majem L, Ribas L, Lloveras G, Salleras L. Changing patterns of fat consumption in Spain. Eur J Clin Nutr 1993;47 (supl 1):13-20.

21. Rodríguez Artalejo F, Banegas JR, Graciani MA, Hernández Vecino R, Rey Calero J. El consumo de alimentos y nutrientes en España en el período 1940-1988. Análisis de su consistencia con la dieta mediterránea. Med Clin (Barc) 1996;106:161-168.

22. Rodríguez Artalejo F, Graciani MA, Banegas JR, Martín-Moreno JM, Sabaté J, Rey Calero $J$. El consumo de alimentos y nutrientes en España en el período 1940-1988 (y II). Un estudio comparativo de las principales fuentes de información sobre consumo alimentario. Med Clin (Barc) 1996;107:446-452.

23. Gordon DJ, Probstfield JL, Garrison JR, Neaton JD, Castelli WP, Knoke JD, et al. High-density lipoprotein cholesterol and car- diovascular disease. Four prospective American studies. Circulation 1989;79:8-15.

24. Stein O, Stein Y. Atheroprotective mechanisms of HDL. Atherosclerosis 1999;144:285-301.

25. Jeppesen J, Hein HO, Suadicani P, Gyntelberg F. Triglyceride concentration and ischemic heart disease: an eight-year follow-up in the Copenhagen Male Study. Circulation 1998;97: 1029-1036.

26. Assmann G, Schulte H, von Eckardstein A. Hypertriglyceridemia and elevated lipoprotein(a) are risk factors for major coronary events in middle-aged men. Am J Cardiol 1996;77:1179-1184.

27. Villar Álvarez F, Banegas JR, Rodríguez Artalejo F, Rey Calero J. Mortalidad cardiovascular en España y sus Comunidades Autónomas (1975-1992). Med Clin (Barc) 1998; I10(9):321-327.

28. Medrano MJ, Almazán J, Sierra MJ, Olalla MT. Siluación epidcmiológica de las enfermedades cardiovasculares arteriocscleróticas (1): mortalidad y morbilidad. Bol Epidemiol Semanal 1998;6:149-153.

29. Villar Álvarez F, Banegas Banegas JR. La mortalidad cardiovascular en España. Rev Sanid Hig Pública 1991;65:5-7.

30. Sans S, Kesteloot H, Kromhout D. The burden of cardiovascular disease mortality in Europe. Task Force on the European Society of Cardiology on Cardiovascular Mortality and Morbidity Statistics in Europe. Eur Heart J 1997;18:1231-1248.

31. Tunstall-Pedoe H, Kuulasmaa K, Mahonen M, Tolonen H, Ruokokoski E, Amouyel P, et al. Contribution of trends in survival and coronary-event rates to changes in coronary heart disease mortality: 10-year results from 37 WHO MONICA Project populations. Lancet 1999; 353:1547-1557.

32. Pérez G, Pena A, Sala J, Roset P, Masiá R, Marrugat $J$. Acute myocardial infarction case fatality, incidence and mortality rates in a population registry in Gerona, Spain, 19901992. Int J Epidemiol 1998;27:599-604.

33. Balaguer Vintró I. Estrategias en el control de los factores de riesgo coronario en la prevención primaria y secundaria. Rev Esp Cardiol 1998;51 (supl 6):30-35.

34. Rodríguez Artalejo F, Banegas Banegas JR, de Andrés Manzano B, del Rey Calero J. Prin- 
cipios de la prevención cardiovascular. Med Clin (Barc) 1999;112:459-464.

35. Wood D, de Backer G, Faergerman O, Graham I, Mancia G, Pyörälä K. Prevention of coronary heart disease in clinical practice. Recommendations of the Second Joint Task Force of Europcan and other Socictics on Coronary Prevention. Eur Heart J 1998; 19: 1434-1503.

36. Kannel WB, Castelli W, Gordon T. Cholesterol in the prediction of coronary heart disease: new perspectives based on the Framingham Study. Ann Intern Med 1979;90:1985-1991.

37. Rose G. La Estrategia de la Medicina Preventiva. Barcelona: Masson-Salvat; 1994.

38. Anderson KM, Wilson PWF; Odell PM, Kannel WB. Un update coronary risk profile. A statement for health professionals. Circulation 1991;83:356-362.

39. Wilson PWF, D'Agostino RB, Levy D, Belanger AM, Silvershatz H, Kannel WB. Prediction of Coronary Heart Disease Using Risk Factor Categories. Circulation 1998; 97:1837-1847.

40. National Cholesterol Education Program. Second Report of the Expert Panel on Detection, Evaluation and Treatment of high blood cholesterol in adults. (Adult Treatment Panell II). Circulation 1994;89:1329-1445.

41. Ministerio de Sanidad y Consumo. Sociedad Española de Cardiología. Consenso para el Control de la Colesterolemia en España. Madrid: MSC; 1990.

42. Grupo de Trabajo de Prevención Cardiovascular. Guía de Prevención Cardiovascular. Madrid: Semfyc; 1996.

43. Villar Álvarez F, Maiques Galán A, Brotons Cuixart C, Torcal Laguna J, Lorenzo Piqueres A, Vilaseca Canals J, et al. Recomendaciones preventivas cardiovasculares: aplicaciones prácticas del riesgo cardiovascular. Programa de Actividades Preventivas y de Promoción de la Salud. Aten Primaria 1999;24 (supl 1): 66-75.

44. Lago Deibe F, Abad Vivas Pérez JJ, Álvarez Cosmea A, Blasco Valle M, Álamo Alonso AJ, Llor Vila C, et al. Dislipemias. Manejo de las dislipemias en atención primaria. Recomendaciones SEMFYC. Madrid: Emisa; 1997.

45. Doll R, Peto R, Wheatly K, Gray R, Sutherland I. Mortality in relation to smoking: 40 years' observations on male British doctors. BMJ 1994;309:901-911.

46. Comité Nacional para la Prevención del Tabaquismo. Libro Blanco sobre el Tabaquismo en España. Barcelona: Glosa; 1998.

47. He J, Vupputuri S, Allen K, Prerost MR, Hughes J, Whelton PK. Passive smoking and the risk of coronary heart disease. A metaanalysis of epidemiologic studies. $\mathrm{N}$ Engl $\mathrm{J}$ Med 1999;340:920-926.

48. MacMahon S, Peto R, Cutler J, Collins R, Sorlie P, Neaton J, et al. Blood pressure, stro$\mathrm{ke}$, and coronary heart disease. Part 1 , prolonged differences in blood pressure: prospective observational studies corrected for the regression dilution bias. Lancet 1990:335:765-774.

49. Aranda P, Banegas JR, Barajas R, Luque M, Rodicio JL. Diagnosis and therapeutic management of hypercholesterolemic spanish hypertensives. J Hypertens 1999;17 (supl 3): 192.A.

50. Hayakawa H, Raij L. Relationship between hypercholesterolemia, endotelial dysfunction and hypertension. J Hypertens 1999;17:611619.

51. Collins R, Peto R, MacMahon S, Hebert P, Fiebach NH, Eberlein KA, et al. Blood pressure, stroke, and coronary heart disease. Part 2, short-term reductions in blood pressure: overview of randomised drug trials in their epidemiological context. Lancet 1990;335:827-838.

52. Laakso M, Lehto S. Epidemiology of macrovascular disease and diabetes. Diabetes Rev 1997;5:294-315.

53. González Santos P, Herrera Pombo JL, Ascaso JF, Escobar Jiménez F, Gómez Gerique JA, Jiménez Perepérez JA, et al. Dislipemia diabética: Documento de consenso de la Sociedad Española de Diabetes y la Sociedad Española de Arteriosclerosis. Av Diabetol 1998;14: 33-43.

54. American Diabetes Association. Management of Dyslipidemia in Adults with Diabetes (Position Statement). Diabetes Care 2000;23 (supl 1):57-60.

55. Pyorala K, Pedersen TR, Kjekshus J, Faergeman O, Olsson AG, Thorgeirsson G. Cholesterol lowering with simvastatin improves prognosis of diabetic patients with coronary heart disease. A subgroup analysis of the 
Scandinavian Simvastatin Survival Study (4S). Diabetes Care 1997;20:614-620.

56. Haffner SM, Lehto S, Ronnemaa T, Pyorala K, Laakso M. Mortality from coronary heart disease in subjects with type II diabetes and nondiabetic subjects with and without prior myocardial infarction. N Engl J Med 1998;339: 229-233.

57. Mabuchi H, Koizumi J, Shimizu M, Takeda R. Development of coronary heart disease in familial hypercholesterolemia. Circulation 1989;79:225-232.

58. WHO. Human Genetics Programme. Familial Hypercholesterolemia. Ginebra: WHO; 1998.

59. Bruin T, Castro M, Dallinga-Thie G, Erkelens W. Familial Combined Hyperlipidemia-do we understand the pathophysiology and genetics? En: Betteridge J (ed). Lipids: Current Perspectives. Londres: Martin Dunitz Ltd; 1996:101-114.

60. Goldstein JL, Hazzard WR, Schrott HG, Bierman EL, Motulsky AG. Hyperlipidemia in coronary heart disease. I. Lipid levels in 500 survivors of myocardial infarction. J Clin Invest 1973;52:1533-1543.

61. Berenson GS, Srinivasan SR, Bao WB, Newman WP, Tracy RE, Wattigney WA, for the Bogalusa Heart Study. Association betwecn multiple cardiovascular risk factors and atherosclerosis in children and young adults. $\mathrm{N}$ Engl J Med 1998;338:1650-1656.

62. Plaza Pérez I, Grupo de Expertos de las Sociedades Española de Arteriosclerosis, Cardiología, Pediatria, Nutrición y Medicina Preventiva. Informe sobre el colesterol en niños y adolescentes españoles. Clin Invest Arterioscl 1991;3:47-66.

63. Rich-Edwards JW, Manson JE, Hennekens $\mathrm{CH}$, Buring JE. The primary prevention of coronary heart disease in women. $\mathrm{N}$ Engl $\mathrm{J}$ Med. 1995;332:1758-1766.

64. Rodríguez Artalejo F. La enfermedad cardiovascular en la mujer. Aten Primaria 1998;22 (Supl 1):200-205.

65. Mosca L, Grundy S, Judelson D, King K, Limacher M, Oparil S, et al. Guide to Preventive Cardiology for Women. Circulation 1999;99:2480-2484.

66. La Rosa JC. Dyslipoproteinemia in women and the elderly. Med Clin North Am 1994; 78:163-180.
67. Rubin SM, Sidncy S, Black DM, Browner WS, Hulley SB, Cummings SR, et al. High blood cholesterol in elderly men and the excess risk for coronary heart disease. Ann Intern Med 1990;113:916-920.

68. Sociedad Española de Arteriosclerosis. Dieta y enfermedades cardiovasculares: recomendaciones de la Sociedad Española de Arteriosclerosis. Clin Invest Arterioscl 1994;6:43-61.

69. Aranceta J. Objetivos nutricionales y guías dietéticas. Propuesta de la SENC para la población española. En: Serra Majem Ll, Aranceta Bartrina J, Mataix Verdú J, editores. Documento de Consenso. Guías alimentarias para la población española. Barcelona: SG, 1995.

70. Hertog M, Kromhout D, Aravanis C, Blackburn H, Buzina R, Fidanza F, Giampaoli S, Jansen A, et al. Flavonoid intake and longterm risk of coronary heart disease and cancer in the Seven Countries Study. Arch Intern Med 1995; 155:381-386.

71. Gay K, Puska P, Jordan P, Moser U. Inverse correlation between plasma vitamin $E$ and mortality from ischemic heart disease in crosscultural epidemiology. Am J Clin Nut 1991; 53:326S-334S.

72- Sierra MJ, Medrano MJ, Almazán J, Olalla MT, López-Abente $\mathrm{G}$. Variaciones provinciales en el contenido de folatos, B 12 y B6 y mortalidad cardiovascular. Rev Esp Salud Pública 1988; 72 (supl): 145 .

73. Carmena R, Ascaso JF, Serrano S, MartínezValls J, Arbona C, Sánchez-Juan C. Modificaciones de las lipoproteínas y apolipoproteínas plasmáticas inducidas por aceite de oliva y aceite de girasol en sujetos normales. Clin Invest Arterioscl 1989;1:10-15.

74. Mata P, Álvarez-Sala L, Rubio M, Nuño J, Oya $M$. Effects of long-term monounsaturated-vs polyunsaturated-enriched diets on lipoproteins in healthy $\mathrm{men}$ and women. Am J Clin Nutr 1992;55:846-850.

75. Pérez-Jiménez F, Espino A, López F, Blanco J, Ruiz V, Prada J, et al. Lipoprotein concentrations in normolipidemic males consuming oleic acid-rich diets from two different sources: olive oil and oleic acid-rich sunflower oil. Am J Clin Nutr 1994;62:769-775.

76. Mata P, Alonso R, Lopez-Farre A, Ordovas JM, Lahoz C, Garces C, et al. Effect of dietary fat saturation on LDL oxidation and monocyte 
adhesion to human endothelial cells in vitro. Arterioscler Thromb Vasc Biol 1996;16:13471355.

77. Mata P, Varela O, Alonso R, Lahoz C, Oya M, Badimon L. Monounsaturated and polyunsaturated $n-6$ fatty acid-enriched diets modify LDL oxidation and decrease human coronary smooth muscle cell DNA synthesis. Arterioscler Thromb Vasc Biol 1997;17:2088-2095.

78. Espino A, López Miranda J, Castro P, Rodríguez M, López-Segura F, Blanco A et al. Monounsaturated fatty acid enriched diets lower plasma insulin levels and blood pressure in healthy young men. Nutr Metab Cardiovasc Dis 1996;6:147-154.

79. Ruíz-Gutiérrez $\mathrm{V}$, Muriana FJ, Guerrero A, Cert AM, Villar J. Plasma lipids, erythrocyte membrane lipids and blood pressure of hypertensive women after ingestion of dietary oleic acid from two different sources. J Hypertens 1996:14:1483-1490.

80. Lahoz C, Alonso R, Ordovas JM, López A, Oya M, Mata P. Effects of dietary fat saturation on eicosanoid production, platelet agregation and blood pressure. Eur J Clin Invest 1997;27:780-787.

81. López-Segura F, Velasco F, López-Miranda J, Castro P, López R, Blanco A, et al. Monounsaturated fatty acid-enriched diet decreases plasma plasminogen activator inhibitor type 1 . Arterioscler Thromb Vasc Biol 1996;16:82-88.

82. Rodríguez Artalejo F, de Andrés Manzano B, Banegas Banegas JR, Guallar Castillón P, Villar Álvarez F, Rey Calero J. La disminución del consumo moderado de alcohol se ha asociado a un descenso de los bebedores excesivos en España en el período 1987-1993. Med Clin (Barc) 1999;113:371-373.

83. US Preventive Services Task Force. Guide to Clinical Preventive Services. $2^{\mathrm{a}}$ ed. Baltimore: Williams and Wilkins; 1996.

84. Ministerio de Sanidad y Consumo. Prevención del tabaquismo. Ayuda a tu paciente a cortar por lo sano. Madrid: MSC; 1998.

85. Marrugat J, Elosúa R, Covas MI, Molina L, Rubiés-Prat J. Amount and Intensity of Physical Activity, Physical Fitness, and Serum Lipids in Men. Am J Epidemiol 1996;143: 562-569.

86. NIH Consensus Development Panel on Physical Activity and Cardiovascular Health. Phy- sical activity and cardiovascular health. JAMA 1996;276:241-246.

87. Downs GR, Clearfield M, Weiss S, Whitney E, Shapiro DR, Beere PA, et al. Primary prevention of acute coronary events with lovastatin in men and women with average cholesterol levels. Results of AFCAPS/TexCAPS. JAMA 1998;279:1615-1622.

88. Fruchart JC, Brewer HB, Leitersdorf E. Consensus for the use of fibrates in the treatment of dyslipoproteinemia and coronary heart disease. Am J Cardiol 1998;81:912-917.

89. Lipid Research Clinics Program. The lipid research clinics coronary primary prevention trial results. I. Reduction of incidence of CHD. JAMA 1984;251:351-364.

90. Frick MII, Elo O, Haapa K, Hcinonen OP, Heinsalmi P, Helo P, et al. Helsinki Heart Study: primary prevention trial with gemfibrozil in middle-age men with dyslipidemia. Safety of treatment, changes in risk factors, and incidence of coronary heart disease. $\mathrm{N}$ Engl J Med 1987;317:1237-1245.

91. Grupo de Trabajo de la Sociedad Española de Arteriosclerosis. Merino Sánchez J, Gómez Gerique JA, eds. Control del paciente dislipémico y factores que afectan al cumplimiento terapéutico. Madrid: IDEPSA; 1998.

92. West of Scotland Coronary Prevention Group. West of Scotland Coronary Prevention Study: identification of high-risk groups and comparison with other cardiovascular intervention trials. Lancet 1996;348:1339-1342.

93. Pekkanen J, Linn S, Heiss G, Suchindran CM, Leon A, Rifkind BM, et al. Ten-year mortality from cardiovascular disease in relation to cholesterol level among men with and without preexisting cardiovascular disease. $\mathrm{N}$ Engl $\mathrm{J}$ Med 1990;322:1700-1707.

94. Wong ND, Cupples LA, Ostfcld AM, Levy D, Kannel WB. Risk factors for long term coronary prognosis after initial myocardial infarction: the Framingham heart study. Am J Epidemiol 1989;130:469-480.

95. Rossouw J, Lewis B, Rifkind BM. The value of lowering cholesterol after myocardial infarction. N Engl J Med 1990;323:1112-1119.

96. Buchwald H, Varco RL, Matts JP, Long JM, Fitch LL, Campbell GS, et al. Effect of partial ileal bypass surgery on mortality and morbidity from 
coronary heart disease in patients with hypercholesterolemia. N Engl J Med 1990;-323:946-955.

97. Knopp RH. Drug Treatment of Lipid Disorders. N Engl J Med 1999;341:498-511.

98. Fuster V, Badimon L, Badimon JJ, Chesebro $\mathrm{JH}$. The pathogenesis of coronary artery disease and the acute coronary syndromes (1). N Engl J Med 1992;326:242-250.

99. Fuster V, Badimon L, Badimon JJ, Chesebro $\mathrm{JH}$. The pathogenesis of coronary artery disease and the acute coronary syndromes (2). N Engl J Med 1992;326:310-318.

100. The Scandinavian Simvastatin Survival Study Group. Randomised trial of cholesterol lowering in 4444 patients with coronary heart disease: the Scandinavian Simvastatin Survival Study (4S). Lancet 1994;344:1383-1389.

101. Sacks FM, Pfeffer MA, Moye LA, Rouleau JL, Rutherford JD, Cole TG, ct al. The effect of pravastatin on coronary events after myocardial infarction in patients with average cholesterol levels. Cholesterol and Recurrente Events Trial investigadoras. N Engl J Med 1996; 335:1001-1009.

102. - The long term intervention with pravastatin in ischaemic disease (LIPID) Study Group. Prevention of cardiovascular events and death with pravastatin in patients with coronary heart disease and a broad range of initial cholesterol lcvels. N Engl J Mcd 1998; 339:1349-1357.

103. - The Post CABG Trials Investigators. The effect of agresiva lowering of low-density lipoprotein cholesterol levels and low-dose anticoagulation on obstructive changes in saphenous-vein coronary-artery bypass grafts. The Post Coronary Artery Bypass Graft Trial Investigators. N Eng J Med 1997;336:153-162.

104. Pitt B, Waters D, Brown WV, Van Boven J, Schwartz L, Title LM, et al. Aggressive lipidlowering therapy compared with angioplasty in stable coronary artery disease. $\mathrm{N}$ Engl J Med 1999;341:70-76.

105. Hebert PR, Gaziano JM, Chan KS, Hennekens $\mathrm{CH}$. Cholesterol lowering with statin drugs, risk of stroke, and total mortality. An overview of randomized trials. JAMA 1997;278:313-321.

106. Gould AL, Rossouw JE, Santanello NC, Heyse JF, Furberg CD. Cholesterol Reduction Yields Clinical Benefit: Impact of Statin Trials. Circulation 1998;97:946-952.
107. Rubins HB, Robins SJ, Collins D, Fye CL, Anderson JW, Elam MB, et al. Gemfibrozil for the secondary prevention of coronary heart disease in men with low levels of high-density lipoprotcin cholcsterol. N Engl J Med 1999;341:410-418.

108. Plaza I, Gómez JA. Cambio de actitud de los cardiólogos españoles respecto al tratamiento hipolipemiante en prevención secundaria de la cardiopatía isquérnica. Clin Invest Arterioscl 1999;11:8-15.

109. Velasco JA, Cosín J, López Sendón JL, de Teresa E, Oya M, et al. La prevención secundaria del infarto de miocardio en España. Estudio PREVESE. Rev Esp Cardiol 1997; 50:406-415.

110. Stafford RS, Blumenthal D, Pasternak RC. Variation in cholesterol management practices of U.S. Physicians. J Am Coll Cardiol 1997; 29:139-46.

111. EUROASPIRE Study Group. A European Society of Cardiology survey of secondary prevention of coronary heart discasc: principal results. European Action on Secondary Prevention through Intervention to Reduce Events. Eur Heart J 1997;18:1569-1582.

112. Singh RB, Rastogi SS, Verma R, Bolaki L, Singh R. Randomised controlled trial of cardioprotective diet in patients with recent acute myocardial infarction: results of one year follow up. BMJ 1992;304:1015-1019.

113. Burr ML, Fehily M, Gilbert JF, Rogers S, Holliday MR, Sweetnam PM, et al. Effects of changes in fat, fish, and fibre intakes on death and myocardial infarction: diet and reinfarction trial (DART). Lancet 1989;2:757-761.

114. De Lorgeril M, Salen P, Martin JL, Monjaud I, Delaye J, Mamelle N. Mediterranean Diet, Traditional Risk Factors, and the Rate of Cardiovascular Complications After Myocardial Infarction: Final Report of the Lyon Diet Heart Study. Circulation 1999; 99: 779-785.

115. GISSI-Prevenzione Investigators. Dietary supplementation with $\mathrm{n}-3$ polyunsatured fatty acids and vitamin $\mathrm{E}$ after myocardial infarction: results of the GISSI-Prevenzione trial. Lancet 1999;354:447-455.

116. The International Task Force for Prevention of Coronary Heart Disease. Coronary Heart Disease: Reducing the Risk. Nutr Metab Cardiovasc Dis 1998;8:205-271. 
117. Dupuis J, Tardif JC, Cernacek P, Theroux P. Cholcstcrol reduction rapidly improves endothelial function after acute coronary syndromes. The RECIFE (reduction of cholesterol in ischemia and function of the endothelium) trial. Circulation 1999;99:3227-3233.

118. WHO. Needs and priorities in cardiac rehabilitation and secondary prevention in patients with coronary artery disease. WHO Technical Report Series 831. Ginebra: WHO;1993.

119. Grupo de Trabajo de Rehabilitación Cardiaca de la Sociedad Española de Cardiología. Rehabilitación del paciente coronario. Prevención Secundaria. Rev Esp Cardiol 1995:48: 643-649.

120. Plaza I, Velasco JA, Maroto JM. Prevención secundaria y rehabilitación cardíaca en España. Rev Esp Cardiol 1996:49:549-553.

121. Joint National Committee on Detection, Evaluation, and Treatment of High Blood Pressu re. The Sixth Report of the Joint National Committe on Prevention, Detection, Eva- luation, and Treatment of High Blood Pressure (JNC-VI). Arch Intern Med 1997;157:24132446.

122. Maroto Montero JM, de Pablo Zarzosa C, Morales Duran MD, Artigao Ramírez R. Rehabilitación Cardiaca. Análisis coste-efectividad. Rev Esp Cardiol 1996;49:753-758.

123. Belardinelli R, Georgiou D, Cianci G, Purcaro A. Randomized, controlled trial of long-term moderate exercise training in chronic heart failure: effects on functional capacity, quality of life, and clinical outcome. Circulation 1999; 99:1173-1182.

124. Comisión de Lípidos y Lipoproteínas de la Sociedad Española de Química Clínica. Métodos recomendados para la determinación de la concentración de colesterol en suero y plasma y en otros especímenes biológicos. Química Clínica 1994;13:496-503.

125. Gómez Gerique JA, Montoya MT. Estandarización de la medición de lípidos y lipoproteínas. Clin Invest Arterioscl 1999;11:28-47. 